\title{
Propietarios, arrendatarios y agregados. Sistemas de tenencia de tierras y relaciones de producción rural en San Miguel de Tucumán, 1770-1820
}

Cristina López de Albornoz

Universidad Nacional de Tucumán

En el trabajo se analizan las características del sistema de tenencia de la tierra vigentes en la jurisdicción de San Miguel de Tucumán entre fines del período colonial y la primera década del independiente. El lapso temporal elegido es particularmente significativo por la conjunción de varios factores, entre los que se destacan el avance de la frontera de ocupación del espacio que se encontraba bajo la órbita del Cabildo local y la definición posterior de la identidad territorial provincial. Ello fue acompañado por un sostenido crecimiento de la población rural, una activa participación campesina en la producción y un significativo desarrollo artesanal. La permanencia de la estructura relacionada con la tenencia de la tierra y las relaciones social-agrarias resultantes, sirvieron de base para el desarrollo posterior del paisaje azucarero de Tucumán, caracterizado por la presencia de un importante sector de medianos y pequeños productores (propietarios y arrendatarios).

“...por último, la manía agradablemente vana de oírse titular dueños de inmensos terrenos, y mas que no posean un grano de trigo; por lo que sólo el derecho de propiedad es toda la suma de entradas que aparece en un pliego de papel que acredita la compra, y fixa los linderos...".

("Sobre las ciudades de la carrera de Buenos Aires al Perú", Semanario de Agricultura, Industria y Comercio de la ciudad de Buenos Aires, 1804-1805).

El objetivo central de esta investigación es analizar las características del sistema de tenencia de la tierra en la jurisdicción de Tucumán durante el lapso temporal comprendido entre 1770 y 1820.

Es importante reconocer que desde mediados del siglo XVIII el espacio comprendido por el nuevo Virreinato del Río de la Plata experimentó una profunda recuperación económica que tuvo su origen en el renacimiento de la actividad minera y la producción de plata de las minas altoperuanas. A ello se sumaron otros factores, como el continuo aumento de la población y el crecimiento de la producción rural. En ese contexto, el espacio ocupado por la ciudad de San Miguel de Tucumán mostró un sostenido incremento de la población de la campaña que se tradujo, a la vez, en una activa partici- 
pación campesina en la producción agraria y el desarrollo artesanal local. Estas transformaciones, cuyos resultados se observan mejor en el orden de la producción y el comercio, no significaron, sin embargo, cambios estructurales en lo social o económico. Mientras el crecimiento económico se operó en el límite de un sistema que carecía de nuevas tecnologías o inversiones de capital, el crecimiento poblacional se vio sujeto a persistentes crisis de mortalidad y generó renovados conflictos entre los grupos sociales, los que se plasmaron en la legislación emanada de los sectores hegemónicos que intentaban sujetar a las clases subalternas. ${ }^{1}$

\section{La sociedad tucumana y su campaña a fines del período colonial}

La ciudad de San Miguel de Tucumán fue fundada en 1565 por don Diego de Villarroel y trasladada en 1685 por don Miguel de Salas y Valdés. Formó parte de la extensa gobernación del Tucumán, que incluía las jurisdicciones de Santiago del Estero, San Miguel de Tucumán, Córdoba, Catamarca, Salta y posteriormente Jujuy y La Rioja. Las primeras entradas en el territorio, bastante tardías respecto a otras regiones, se produjeron en un contexto importante de cambios vinculados con el gobierno y la administración de las colonias hispanas. ${ }^{2}$

El primer asentamiento de la ciudad de San Miguel se ubicó en el sitio de Ibatín, al sur de su actual emplazamiento. Desde allí los españoles extendieron sus chacras y estancias y fijaron las redes de comunicación con las ciudades vecinas. ${ }^{3}$ A fines del siglo XIX la superficie de la provincia era estimada en veintisiete mil $\mathrm{km}^{2}$. Constituyó - y constituye aún hoy- la provincia más pequeña del territorio argentino.

1 López de Albornoz, Cristina: "Control social y economía colonial tucumana. Las "ordenanzas de buen gobierno' y el conchabo obligatorio a fines del siglo XVIII”, en Travesía, 1, Tucumán, 1998, págs. 63-116.

2 Entre esos cambios se encontraban las disposiciones referidas al fin de las encomiendas antiguas y las Leyes Nuevas de 1542 que prohibían, entre otras cosas, el servicio personal como parte de la tributación de las poblaciones indígenas; también se había acelerado el proceso de colonización del territorio americano y se habían dispuesto mayores controles por parte de los funcionarios encargados de la administración colonial.

3 La provisión de Francisco de Aguirre encomendando a Diego de Villarroel la fundación de la ciudad y nombrándolo su teniente de gobernador reza así: “...nombro elixo e proveo a vos el dicho capitán Diego de Villarroel por mi teniente de gobernador e capitán en la ciudad de San Miguel de Tucumán e sus términos, para que como tal mi teniente de gobernador e capitan podáis poblar e pobléis la ciudad e pueblo de San Miguel de Tucumán en el campo que llaman en lengua de los naturales Ybatin ribera del río que sale de la quebrada, en el sitio que os pareciere, rigiéndoos en todo por la instrucción que mía lleváis...", Lizondo Borda, M.: Actas Capitulares de San Miguel de Tucumán, vol. 1, págs. 16-18. 
A pesar de su limitada extensión física Tucumán es un espacio muy rico en contrastes, que incluye las Sierras Subandinas hacia el oeste (con valles de altura de gran accesibilidad) y la llanura chaqueña hacia el este. De norte a sur la provincia se encuentra atravesada por el río Salí (o Grande, como se lo denominaba antiguamente), que concentra una voluminosa red fluvial que distingue a la zona del conjunto regional, caracterizado por la escasez de agua. En el noreste, otra cadena montañosa (las Sierras de Medinas) separa el valle de Tapia-Trancas de la llanura chaqueña. Desde el centro se abre una extensa planicie, también atravesada por el Salí, y lo que propiamente debió denominarse "Tucma", Tucumán o "provincia del Salî". Fue en la llanura central, al occidente del río, donde se estableció la primera ciudad cabecera y se extendió la colonización.

La ocupación del territorio fue en sus comienzos lenta y en muchos casos más nominal que efectiva, pues la región del Tucumán actuó como una doble frontera de la Corona española. Por un lado fue frontera política y económica, pues constituía la región más alejada del Virreinato peruano. Por otro lado, actuó como frontera cultural, y muy a menudo bélica, debido a los continuos enfrentamientos con los antiguos habitantes de la zona. Durante ciento treinta años las poblaciones indígenas calchaquíes del oeste ofrecieron resistencia al sistema colonial español. En algunos casos fue una resistencia pasiva, consistente en no acudir a cumplir con las mitas asignadas. En otros casos fue la confrontación armada. El resultado final culminó con el triunfo de los españoles en 1660 y el posterior extrañamiento de la totalidad de las familias indígenas hacia otros nichos ecológicos. A partir de entonces quedó latente el peligro en la frontera este, que incidió significativamente sobre el desarrollo económico de la región y la ocupación efectiva de muchos espacios ubicados al oriente. Las poblaciones chaqueñas, en gran medida nómadas, eran más difíciles de controlar porque no tenían asentamientos fijos: salían de las entrañas del Chaco, efectuaban sus "correrías" y volvían a internarse en el bosque. Era una guerra ofensiva y defensiva a la vez, pues el español también hacía sus "entradas" en busca del enemigo y obtenía eventualmente alguna victoria, materializada en la captura de unos cuantos indios (especialmente "chinitas"), destinados a servir en las estancias de los soldados. Pero también hay que reconocer que durante extensos períodos de tiempo ese mismo espacio fronterizo actuó como un territorio de intenso intercambio mercantil (legal e ilegal) entre el mundo hispanocolonial y el mundo aborigen. 
El traslado de la ciudad a su nuevo asentamiento en el sitio de La Toma produjo una mayor apetencia por tierras, a la vez que se hizo necesario asegurar las rutas y el tráfico comercial mediante la concentración de población en los fuertes y reducciones de la "frontera". Esto provocó la decisión de algunas autoridades coloniales de "avanzar" sobre el Chaco. Durante los gobiernos de los militares don Esteban Urízar y Arespacochaga y don Victoriano Martínez de Tineo se implementaron medidas políticas vinculadas con la fundación de reducciones administradas por los jesuitas. Desde entonces los españoles lograron controlar relativamente la frontera oriental por lo que los llanos tucumanos del este y la cuenca intermontana de la región central del norte adquirieron valor y fueron efectivamente ocupados. ${ }^{4}$

Al finalizar el siglo XVIII los vecinos y residentes de San Miguel sumaban unos 20.000 habitantes, de los cuales el $80 \%$ vivía en la campaña. La concentración demográfica seguía marcando el ritmo original de la colonización (véase mapa). Sobre la llanura suroccidental se radicaban los principales asentamientos dedicados a la ganadería y las sementeras de maíz y trigo, mientras que en la región montañosa el poblamiento se mantuvo disperso, dificultado por las características del terreno y la presencia de propiedades laicas y religiosas (como las que pertenecieron a la Compañía de Jesús), de mayor extensión y destinadas casi exclusivamente a la ganadería. Veremos más adelante que estas mismas grandes explotaciones (los potreros) generaron otro tipo de poblamiento, asociado con la atracción que ejercían para el asentamiento temporal de mano de obra. La "otra banda", es decir, los terrenos ubicados especialmente en el curato Rectoral y Burruyacu, comenzó a ser colonizada a partir de nuevas mercedes de tierras y el asentamiento de importantes estancias ganaderas. Simultáneamente se

4 Para conocer los efectos de las desnaturalizaciones de las poblaciones calchaquíes se pueden confrontar, entre otros, los trabajos de Lorandi, Ana María: El trabajo y las rebeliones, m.s., 1984; "El servicio personal como agente de desestructuración en el Tucumán colonial", en: Revista Andina, núm. 6 , I, Cuzco, 1988, págs. 135-173; "El mestizaje interétnico en el Noroeste Argentino", en: Tamoeda, H., y Millones, J. (eds.), 500 Años de mestizaje en los Andes, National Museum of Ethnology. Senri Ethnological Studies, núm. 33, Osaka, 1992, págs. 133-167; Lorandi, Ana María y Boixados, Roxana: "Etnohistoria de los valles Calchaquíes en los siglos XVI y XVII", en: Runa, núms.17-18, Buenos Aires, 1987-1988, págs. 221-262; Lorandi, Ana María y Ferreiro, Juan Pablo: "De la crisis a la estabilidad. La sociedad nativa de Tucumán a fines del siglo XVII y comienzos del XVIII", en Memoria Americana, núm. 1, Buenos Aires, 1991, págs. 57-101; López de Albornoz: "Las desnaturalizaciones calchaquíes y sus efectos en las poblaciones trasladadas al valle de Choromoros", en Anuario de Estudios Americanos, tomo XLVII, Sevilla, 1990, págs. 199-240. Juan Carlos Garavaglia: La guerra en el Tucumán colonial. Sociedad y economía en un área de frontera (1660-1760), HISLA, vol. IV, Lima, 1984, págs. 21-33. 
TENENCIA DE TIERRAS EN SAN MIGUEL DE TUCUMÁN, 1770-1820

Población de los curatos de la campaña de San Miguel de Tucumán según padrones de 1799, 1812 y 1816

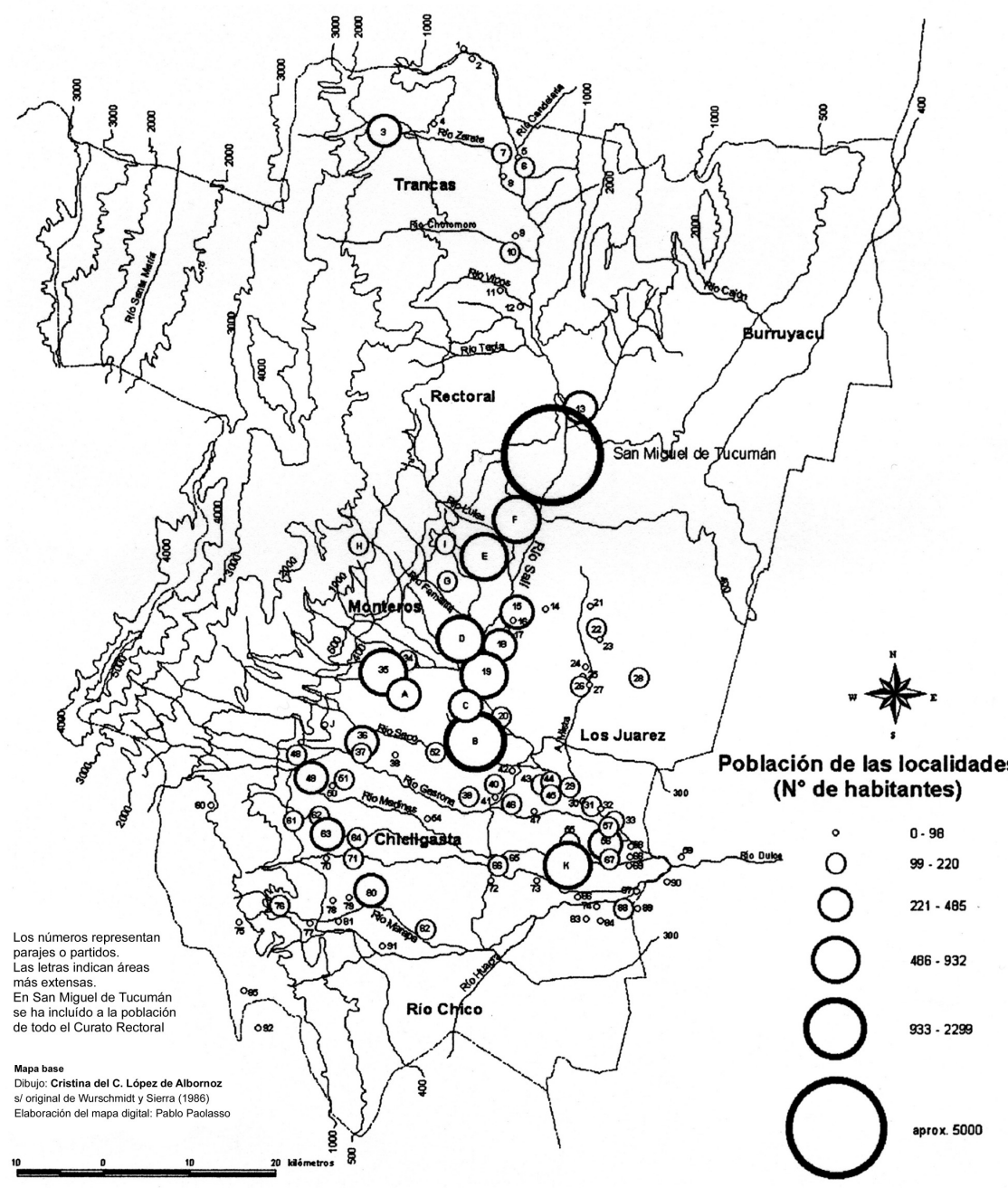


fue produciendo el desplazamiento de grupos familiares de menores recursos que se instalaron en las zonas menos favorecidas por la escasez de agua o la calidad de los suelos (como ocurrió en Los Juárez).

A pesar de los vaivenes de la colonización, la ciudad de Tucumán consolidó su presencia a través de la actividad económica basada en la producción ganadera y artesanal y el intercambio mercantil.

\section{Sistemas de tenencia de tierras}

El valor de la tierra es fundamental en las sociedades agrarias, tanto como factor de producción como eventualmente de cambio: las posibilidades de reproducción social de las familias rurales dependen de ello. Pero también es importante sumarle al valor económico el factor de prestigio y símbolo de poder que la tierra concedió a los propietarios en las sociedades del Antiguo Régimen. Justamente uno de los privilegios del sistema corporativo sobre los fueros y los bienes lo constituyó el acceso a la titularidad de un terreno. Ambos temas constituyen parte del debate relacionado con el valor rentístico y/o simbólico de las propiedades inmobiliarias rurales, cuyas interpretaciones parcializadas resultan insuficientes para explicar las persistencias y cambios que se observan en la sociedad tardocolonial americana.

La tarea de delimitar con precisión el universo de los propietarios y no propietarios del período colonial del Tucumán, reviste importantes dificultades vinculadas con la carencia de censos y padrones catastrales, la irregularidad que presentan los títulos de propiedad y las prácticas referidas a acuerdos privados y procedimientos extrajudiciales que afectaron a las transacciones y operaciones de transferencia de la tierra. Tampoco es fácil mensurar el nivel de estabilidad o inestabilidad dominial que caracterizó a la región. A pesar de ello, es importante esbozar un panorama respecto a la distribución de los inmuebles rurales en el marco de los cambios ocurridos a fines del siglo XVIII, a la vez que estimar el papel del Estado en esta materia. El estudio que se lleva a cabo en este trabajo no se limita a las propiedades y los propietarios jurídicamente reconocidos, sino que se extiende a otros tipos de tenencias destinadas a la producción. Sin dudas, la documentación es más generosa en datos y referencias sobre el sector de propietarios, lo que nos ha permitido profundizar en diferentes aspectos. Sin embargo, en uno y otro caso no podemos olvidar qué prácticas, usos y 
costumbres caracterizaron la tenencia y transferencia de las tierras y que las relaciones de producción del agro tucumano se fundaron en lazos de parentesco, vecindad, protección y dependencia. Sólo considerando el valor central de estas prácticas es posible entender los sistemas de tenencia y de producción, pues tales usos y costumbres se reflejaron necesariamente en las relaciones sociales agrarias.

En el origen de la colonización americana el acceso a la propiedad privada de la tierra sólo era posible mediante una merced otorgada por la Corona o las autoridades locales de turno, que de este modo premiaban a quienes habían participado de la conquista y primeras "entradas" al territorio. Con el tiempo, el acceso a la titularidad de un terreno se fue ampliando mediante otros mecanismos, como la herencia, la donación y la compra.

La abundante disponibilidad de tierras que había caracterizado los primeros tiempos permitió una extensiva distribución de este recurso entre los pocos colonizadores españoles que se asentaron en las diferentes regiones, en la mayoría de los casos, a expensas de las poblaciones originarias. Al finalizar el período colonial los terrenos destinados a la producción - especialmente aquellos más aptos y cercanos a los mercados-, se había vuelto un recurso relativamente escaso en las zonas pobladas del continente. $\mathrm{La}$ recuperación demográfica de la población, el influjo del capital minero y comercial y el crecimiento de los mercados urbanos, generaron, a partir de la segunda mitad del siglo XVIII, una mayor demanda de tierras rurales. Ello produjo un proceso de expansión de la frontera de ocupación que terminó incorporando terrenos marginales disputados a las poblaciones indígenas sobrevivientes (como ocurrió en la frontera chaqueña) y las propiedades ocupadas con títulos dudosos, las de las familias con menores recursos y las antiguas tierras comunales de los pueblos sometidos.

A fines del período colonial el panorama relacionado con la tenencia de tierras en la jurisdicción de San Miguel era muy diverso y se encontraba sujeto a permanentes transformaciones. Persistían las mercedes de tierras concedidas a los vecinos "beneméritos", junto a los condominios de herederos o tierras indivisas. Se habían multiplicado los predios adquiridos por compras y las tierras obtenidas por donaciones y permutas. Sobrevivían también algunas propiedades comunales de pueblos de indios, aunque en marcada retracción por las persistentes usurpaciones. Todas estas formas estaban relacionadas con derechos jurídicos reconocidos sobre la propiedad inmueble. Pero la mayor parte del suelo agrario local era explotado por productores no propietarios que vivían de la cría de pequeños rebaños de 
vacunos, equinos y ovinos y de la siembra de maíz y hortalizas. Estos productores se valían de la fuerza de trabajo familiar y destinaban sus beneficios para el autoconsumo y el intercambio en pequeña escala. ${ }^{5}$

La difusión de los pequeños productores rurales (propietarios, arrendatarios, agregados a las estancias) fue un proceso concomitante con el acrecentamiento de algunos establecimientos familiares de particular extensión y generó una transformación de la fisonomía de la campaña. El origen de estos sistemas y su extensión difícilmente pueden adjudicarse a una única causa, sino a la suma de ellas. El aumento de la población, la modificación de las estructuras indígenas y la desaparición de la encomienda, así como la formación de un sector de trabajadores libres que pudo acceder a la compra o herencia de la tierra, favorecieron el acceso a parcelas para la producción. El precio deprimido, que se mantuvo constante durante gran parte del período, facilitó su adquisición. El crecimiento de la demanda interna de productos agrícolas y efectos de exportación provocó la necesidad de utilizar, incluso, las tierras marginales de las estancias, permitiendo la diversidad de arreglos entre los productores rurales y los propietarios, y generando que la oferta relativa de tierras no explotadas se combinara con la "escasez" de mano de obra necesaria para hacerlas producir, sin que ello alterara demasiado la estructura de la propiedad agraria local. ${ }^{6}$

\section{Los propietarios}

La campaña tucumana se caracteriza por una especial y considerable parcelación de las tierras y por un alto porcentaje de propietarios. Parte de la explicación del fenómeno hay que buscarla en la gran difusión de propiedades indivisas, la ausencia de registros catastrales y la falta de docu-

5 López de Albornoz, Cristina: "Población, familia y producción agraria en la jurisdicción de San Miguel de Tucumán (1790-1815)”, en XVI Jornadas de Historia Económica, Quilmes, 1998.

6 Este último punto ha generado un intenso debate entre los historiadores del siglo XVIII y comienzos del XIX (que hoy se reconoce como la "vieja polémica" que dio nuevo impulso a los estudios agrarios del Río de la Plata), vinculado con la escasez o no de trabajadores en un contexto de crecimiento demográfico generalizado. Desde los análisis que he podido llevar a cabo sobre la jurisdicción de Tucumán, la escasez de mano de obra para la producción rural se presenta como una escasez estructural, asociada con la posibilidad de que gran parte de la población rural tuviera acceso a medios alternativos de subsistencia (incluso mediante la explotación de una parcela de tierra sin ser propietario) que le mantenía al margen de la necesidad de emplearse en condición de dependiente de las estancias. Las quejas de los estancieros tienen que ver, en todo caso, con la necesidad estacional de fuerza de trabajo y con la competencia con la producción campesina. 
mentación específica. De todos modos debemos aclarar que el creciente interés por deslindar terrenos y legitimar la posesión se acentuó a partir de 1790, acelerando el proceso de identificación de los titulares. ${ }^{7}$ A fines del siglo XVIII el porcentaje de propietarios era considerable pues oscilaba entre el 10 y el $15 \%$, según las regiones. ${ }^{8}$

Todo título de propiedad requería del acto de posesión judicial que le otorgaba validez legal. El procedimiento incluía un ceremonial de reconocimiento por parte de los vecinos colindantes y la legitimación de la posesión por parte de los jueces correspondientes. Ello no impedía que los vicios de forma, la falta de mensuras y la ausencia de registros de los títulos, invalidaran el acto. Los numerosos pleitos por tierras conservados en el archivo local son ilustrativos de estas situaciones y se proyectan hasta mediados del siglo XIX. ${ }^{9}$ Allí se ventilan problemas de linderos, asentamientos ilegales, usurpaciones, problemas de acceso al agua. ${ }^{10}$ Estos pleitos presentados ante la justicia, sin embargo, sólo reflejan un universo muy acotado de los problemas sobre la propiedad y tenencia de la tierra pues los acuerdos extrajudiciales fueron una práctica extendida para resolver situaciones vinculadas con límites territoriales y cuestiones conexas.

Tal como hemos adelantado, el origen legal de la propiedad sobre las tierras rurales americanas fueron las mercedes reales concedidas a los vecinos que habían participado en la conquista y colonización del territorio, a las que se sumaron las "composiciones" que permitieron legalizar situaciones

7 López de Albornoz, Cristina: El derecho a las tierras en San Miguel del Tucumán a la luz de la documentación de los siglos XVI y XVII, Informe al CONICET, 1989.

8 El alto porcentaje de propietarios de terrenos rurales no es un fenómeno aislado en la gobernación, pues la jurisdicción de Córdoba presentaba un porcentaje de $13 \%$ de propietarios a mediados del siglo XIX. En Tucumán, el proceso fue distorsionándose hasta producir una mayor concentración de tierras hacia fines del siguiente siglo, cuando se registró un 7\% de propietarios rurales: Bousquet, Alfredo etal., Memoria Histórica y descriptiva de la Provincia de Tucumán, Buenos Aires, 1882.

9 López de Albornoz, Cristina: "Vivir y trabajar en los campos tucumanos a fines de la colonia y comienzos de la independencia", Tesis de Maestría. Universidad Internacional de Andalucía, La Rábida, 1998; Fernández Murga: "La tierra en Tucumán en la primera mitad del siglo XIX”, Tesis de Maestría, Universidad Internacional de Andalucía, La Rábida, 1998.

10 Entre los expedientes judiciales sólo hemos localizado un pleito por el agua (en realidad, por una huerta y su acequia), pero también se registró una venta de derechos sobre el agua. En 1808, don José Parellón vendió a don Pedro Lobo, ambos vecinos con estancias en la parte oriental del río de la ciudad, "el goce y disfrute del agua del cauce o acequia que tiene sacada del río y costeada a sus expensas para el cultivo y beneficio de su Estancia", por valor de 100 pesos. Eso le daba derechos a Lobo, vecino de Parellón, al uso del agua para el beneficio de su terreno con la obligación de que el comprador debía "concurrir con Gente o dinero para el cuidado, reparo y conservación de la acequia y bocatomas con arreglo al usufructo común”. Archivo Histórico de Tucumán (en adelante AHT) Sección Protocolos (en adelante SP), Serie A, vol. 17, fs. 122-125v. del año 1808. 
dudosas mediante el pago de un monto de dinero destinado a las arcas reales. Por su propia condición de frontera, la región del Tucumán se caracterizó por una extendida práctica de otorgamiento de mercedes reales que se prolongó hasta fines del siglo XVIII. Las frecuentes entradas al valle Calchaquí y al Chaco alentaron las posibilidades para que militares y aventureros pudieran convertirse en propietarios de tierras. Más allá de las dimensiones territoriales de estas propiedades (que en algunos casos alcanzaron dos y tres leguas), ${ }^{11}$ la merced representaba el reconocimiento de prestigio y estatus de sus beneficiarios. En torno a ellas se construyeron los linajes locales, con una marcada endogamia de grupo y sólidas alianzas familiares.

Con el tiempo estas grandes mercedes fueron desapareciendo por efecto del fraccionamiento producido por las herencias, las dotes, las donaciones y las compraventas, dando origen a los asentamientos poblacionales que se registraron en los censos de fines del siglo XVIII y comienzos del XIX. El proceso de parcelación de las tierras fue fundamentalmente el resultado de la aplicación del derecho castellano: la herencia no estaba ligada a vínculos de primogenitura, por lo que los bienes debían dividirse entre todos los hijos en partes iguales. La práctica testamentaria, no obstante, nos permitió advertir algunas estrategias familiares que intentaban evitar el fraccionamiento. ${ }^{12}$ El peso de la costumbre generalizó la posibilidad de la transmisión patrimonial concentrada en alguno de los descendientes. A veces se hacía a través de las órdenes expresas que recibían los albaceas. En otras, mediante el establecimiento de capellanías, legados intervivos, donaciones. La exclusión (especialmente de las mujeres) fue una práctica común, aunque encubierta tras la dote o el adelanto de la herencia. La otra estrategia pasaba por el reconocimiento de la primogeni-

11 Debemos aclarar que la extensión de la legua que hemos utilizado aquí es en todos los casos la de 5.000 varas castellanas (4.330 metros) y la legua cuadrada de 1.875 has. La elección no es arbitraria. De acuerdo a la documentación que hemos consultado, la legua se medía en 100 sogas y cada soga contaba, a su vez, con 50 varas aproximadamente. También se puede consultar la Memoria descriptiva de la provincia de Tucumán, 1876, pág. 581 y Zavalía Matienzo: Los límites de la provincia de Tucumán a la luz del derecho y de la historia, Publicación del Archivo Histórico de Tucumán, Serie Especial núm. XXIV, vol I, Tucumán, 1972.

12 Hasta hace poco tiempo la historiografía vinculada al estudio de las élites americanas establecía una relación directa entre las normas referidas a la herencia, correspondientes al sistema castellano, y la dispersión patrimonial que las mismas provocaban tras su aplicación. Las leyes castellanas determinaban la herencia igualitaria entre los descendientes, sin distinción de géneros. Ello habría generado la ruina de muchas familias cuyas fortunas debieron ser repartidas proporcionalmente entre los herederos. Nuevas investigaciones revelan el carácter conflictivo que conllevaba la transmisión del patrimonio en el interior de los grupos familiares y han demostrado que fueron en general el resultado de una sucesión de transacciones y estrategias implementadas al margen de las leyes. 
tura, aunque sin exclusión de los demás herederos. Esto último se hacía mediante las mejoras del quinto y el tercio que recaían en alguno de los hijos. Muchas propiedades permanecieron "indivisas" por largo tiempo, incluso por varias generaciones, pero luego la parcelación se instauró de hecho pues los herederos tendían a vender sus partes, generando posteriores pleitos por deslindes y derechos sucesorios.

El proceso de mercantilización de las tierras se advierte ya desde fines del siglo XVII, aunque alcanzó una mayor aceleración desde la segunda mitad del XVIII. Al finalizar el período colonial los propietarios particulares de establecimientos rurales constituían un grupo diverso no sólo en relación con la extensión y mejoras de las tierras, sino fundamentalmente por su inserción social y política, sus patrones de residencia y sus estrategias económicas.

Propiedad de la tierra y producción no fueron sinónimos en el mundo colonial, como tampoco hubo una homología entre estanciero y propietario. Pero la propiedad inmobiliaria estuvo, por lo general, asociada con el grupo que formaba parte de la cúspide de la pirámide social, a la vez que la tierra y la familia condicionaron poderosamente el funcionamiento de otros principios de la organización social colonial, estamental y patrimonial. Por otro lado, en las sociedades preindustriales, el control sobre la propiedad rural es importante porque permite el manejo de la fuerza de trabajo. Ello origina una dependencia de los grupos no propietarios respecto de los propietarios.

La propiedad jurídica de una parcela, una estancia, chacra o potrero cumplía una función fundamental entre las familias rurales: permitía u obligaba a la colaboración entre unidades domésticas no corresidentes, subordinaba a los hijos en las estrategias complejas de alianzas y apoyo con otros grupos familiares, generaba prácticas de transmisión patrimonial para evitar el fraccionamiento excesivo. No debe extrañarnos entonces que, al hacer este análisis sobre los propietarios rurales de Tucumán, los apellidos de las familias se confundan con la denominación de los parajes en una enmarañada red de parentescos, pleitos y alianzas. ${ }^{13}$

13 La familia involucra el sistema de parentesco que es ante todo un sistema de relaciones que no tiene existencia material directamente perceptible, pero que combina consanguinidad y alianza y puede expresarse en términos de parentesco real/parentesco espiritual, éste último definido y ritualmente marcado, fundamentalmente, por el bautismo (y los padrinos de bautismo). Guerreau-Jalabert: "El sistema de parentesco medieval: sus formas (real/espiritual) y su dependencia con respecto a la organización del espacio" en: Pastor, Reyna (comp.), Relaciones de poder, de producción y parentesco en la Edad Media y Moderna. Aproximación a su estudio, Madrid, 1990, tomo 1, págs. 85-105. 
La subordinación de la producción agraria respecto a la circulación mercantil permite entender cómo fueron modificándose los patrones de residencia de los grupos propietarios más importantes. El crecimiento y renovado rol de la ciudad de San Miguel como centro articulador de la economía regional, junto a la radicación de comerciantes de origen español, permitió la consolidación de los patrones de asentamiento urbano de los vecinos tucumanos. Antiguos encomenderos y estancieros de la jurisdicción instalaron sus casas, tiendas, cuartos de alquiler y carpinterías en la ciudad, dejando sus posesiones rurales a cargo de terceros, generalmente parientes, con funciones de capataces y administradores de las haciendas. Los pequeños y medianos comerciantes y fleteros hicieron lo propio, adquiriendo solares y casas en San Miguel y algunas parcelas de tierras en el área rural, con lo que diversificaron sus inversiones y generaron un doble patrón de residencia.

En la campaña sobrevivían los descendientes de antiguas familias, medianos y pequeños productores de extracción social más baja cuyos capitales provenían del comercio o el conchabo como capataces, algunos esclavos beneficiarios de las donaciones de sus patrones y amos, inmigrantes de las regiones vecinas y un importante grupo constituido por residentes campesinos, en su mayoría sin acceso a la propiedad de la tierra.

\section{CUADRO 1}

\section{SISTEMAS DE TENENCIA DE TIERRAS RECONOCIDOS} EN TUCUMÁN (1750-1820)

\begin{tabular}{lll} 
Propietarios & Arrendatarios & Agregados \\
\hline Laicos & c/pago de arriendo & peones de estancia \\
Clero Secular & "de gracia" & familias que viven en tierras \\
Regular & & de estancia
\end{tabular}

Pueblos de indios

El conjunto de propietarios incluía tanto a laicos como a religiosos, tanto del clero secular como de las órdenes religiosas. Los miembros del clero secular tenían acceso a la propiedad a través de las herencias, donaciones, patrimonios laicales y compras de tierras, por lo que sus patrimonios quedaron sujetos a las leyes de sucesión aplicadas a cualquier propietario laico. El destino de estas propiedades estuvo condicionado por las estrategias implementadas por los grupos familiares. Las órdenes religiosas y los conventos, por otro lado, conformaron sus patrimonios mediante la 
intervención directa en el mercado inmobiliario y las donaciones intervivos y de cláusula testamentaria que les solían hacer los fieles. El otro mecanismo de acceso a las tierras lo constituyeron las capellanías y censos que gravaban las propiedades de los particulares y que, a la larga, pasaban a integrar el patrimonio de las órdenes.

Entre este último grupo, la Compañía de Jesús fue la que se destacó en la jurisdicción por sus estrategias de acumulación de inmuebles y los volúmenes de producción ganadera y artesanal que manejaba anualmente, evidenciando una clara actitud de racionalidad económica destinada a generar excedentes para el mercado interno y regional. ${ }^{14}$

Antes de su expulsión en 1767, esta Orden contaba con dos complejos productivos pertenecientes a los colegios de San Miguel (que se articulaba en torno a la Hacienda de Lules) y el de Santiago del Estero (cuyo centro era la Estancia de San Ignacio). El Colegio de Santa María Magdalena se había convertido en el propietario más poderoso de tierras rurales de Tucumán. Contaba con casi cuatrocientas mil hectáreas en la zona de piedemonte, la llanura y los valles intermontanos. El complejo sistema de apropiación de tierras había incluido mercedes, donaciones, compras, trueques y pleitos entablados con otros propietarios. Similar estrategia había utilizado el Colegio de Santiago del Estero, que también había logrado adueñarse de vastas extensiones de tierras al sur de la jurisdicción.

Las características propias de la explotación de los inmuebles rurales permiten sostener que la rentabilidad de los establecimientos se obtenía con un margen de control de riesgos que muchas veces no era posible para los propietarios particulares. A diferencia de éstos últimos las corporaciones eclesiásticas, como la Compañía de Jesús, gozaban de acceso directo a capitales líquidos que obtenían a través de donativos privados. Eso les permitía invertir en forma redituable prestando dinero a los estancieros más

14 El sistema de apropiación de tierras y de producción aplicado por el colegio de Santa María Magdalena y por el colegio de Santiago del Estero formó parte de un macrosistema institucionalizado por la Compañía de Jesús para todos los colegios de la Orden. Sus modalidades de inversión, negocios y demás actividades económicas estaban destinadas a permitir el autoabastecimiento de todos los establecimientos y generar excedentes para sostener las necesidades de los colegios. A su vez, el respaldo que ofrecía la Orden a sus diferentes representantes permitía superar los períodos de crisis. En estas actividades los padres de la Compañía asociaron a miembros importantes de la sociedad civil, muchos de los cuales se vieron seriamente afectados con la expulsión. Para ampliar sobre este tema, véase López de Albornoz, Cristina: "Incidencia de la venta de los inmuebles de las Temporalidades en la estructura agraria de Tucumán", presentado en las XIV Jornadas de Historia Económica, Córdoba, 1994; Robledo: "El espacio jesuítico de San Miguel de Tucumán”, en Actas del Primer Congreso de Investigación Social, Tucumán, 1996. 
importantes, a la vez que movilizaban la producción comprando esclavos y contratando mano de obra para tareas estacionales. La situación no era tan ventajosa a la hora de ingresar al mercado para vender sus productos, pues el mantenimiento de los Colegios urbanos, el culto y los propios establecimientos productivos obligaba a vender en condiciones aún adversas, con lo que el comportamiento de estas instituciones se asemejaba, en períodos de crisis, a las casi nulas oportunidades de los campesinos. ${ }^{15}$

La desaparición de este poderoso propietario generó, por un lado, la posibilidad de que los particulares accedieran a las tierras, provocando una devaluación de las parcelas ante la excesiva oferta de inmuebles. Pero, por otro lado, la eliminación de la competencia con la Compañía de Jesús produjo un reordenamiento de los sectores productivos, sociales y de poder, especialmente entre aquellos que habían estado asociados con las actividades que desarrollaban los jesuitas. Luego de la expulsión muchos vecinos tucumanos vieron afectadas sus relaciones comerciales, patrimoniales y de producción. ${ }^{16}$

Otro grupo de titulares de tierras que durante el período colonial tuvo un particular protagonismo en la región fue el de los pueblos de indios que tenían derechos sobre las propiedades comunales. Hacia fines del siglo XVIII sobrevivía una docena de pueblos indios en la jurisdicción de Tucumán, sujetos a tributación a la Corona y con una marcada diferenciación social y económica intra e intercomunal. Reunían en su interior el 5\% de la población aborigen local, que se completaba con los descendientes que habían cambiado su estatus jurídico y escapaban a la condición de tributarios. Sin extendernos demasiado en el tema, que ha sido tratado en otros trabajos, nos interesa destacar aquí en qué consistían los derechos de propiedad de las poblaciones nativas.

De acuerdo con la legislación indiana, los pueblos originarios no debían ser hostigados en los derechos sobre sus propiedades. ${ }^{17}$ El espíritu de la

15 Gelman, Jorge: "Los caminos del mercado. Campesinos, estancieros y pulperos en una región del Río de la Plata colonial”, en Latin America Research Review, vol. 28, n. ${ }^{\circ}$ 2, New México, 1993, págs. 89-118.

16 Antes de su expulsión, la Compañía de Jesús tenía intereses en todas las empresas agrícolas y propiedades importantes de la provincia. Comerciantes de Santa Fe y Córdoba, así como del Alto Perú, funcionarios locales y regionales, estancieros y curas vinculados por lazos de parentesco y sociedades comerciales con la Orden integraron las listas de quienes trataron con los jesuitas durante el período de su accionar.

17 Las autoridades competentes debían cuidar que las mercedes de tierras no se hicieran "en perjuicio de los naturales" y que los repartimientos de indios "no implicasen el ejercicio de ninguna jurisdicción sobre las tierras de los habitantes concedidos en encomienda" (Solórzano Pereira, Juan de: Política Indiana, Madrid, 1930). 
ley procuraba que el indio no se desvinculara de la tierra pues ello atentaba contra la producción y su capacidad tributaria. De más está decir que la codicia de los encomenderos y las prácticas de la mita y el servicio personal afectaron directamente la posibilidad de preservación de los derechos comunitarios. Además de ello, la inalienabilidad de estas tierras, o de los derechos sobre ellas, es cuestionable pues hubo numerosos casos de ventas de las propiedades por presión de los vecinos feudatarios y las autoridades de turno. ${ }^{18}$

Las características específicas de los condominios constituidos por las propiedades comunales y los derechos que otorgaban a cada familia del pueblo son muy confusos. Aparentemente las tierras se repartían entre los grupos familiares para que pudieran producir para su subsistencia, pero se reservaban tierras comunes con pastos, aguadas y maderas para provecho del pueblo. Esas tierras comunes podían ser usufructuadas por la comunidad o, como ocurrió en el pueblo de Colalao y Tolombón, podían ser arrendadas a terceros. Los derechos de las familias sobre la propiedad tampoco son claros, aunque parecen haber estado relacionados con la condición de ser "indio originario", es decir natural de la comunidad. Los "foráneos" sólo podían acceder a las tierras mediante el matrimonio con algún miembro del pueblo. ${ }^{19}$ Lo cierto es que los derechos comunales parecen haber permitido a los propietarios establecer estrategias vinculadas con las prácticas matrimoniales que incluían una marcada endogamia entre los originarios y accesos más restringidos para los foráneos e individuos de otras etnias. Por otro lado, la propiedad comunal hizo posible la aplicación de prácticas de producción similares a las utilizadas por los estancieros, como el arrendamiento de tierras por ejemplo. El cobro del canon sobre los arriendos permitía a la población tributaria hacer frente a las exigencias fiscales impuestas por el Estado.

Por lo demás, las familias propietarias de los pueblos de indios integraban el conjunto de pequeños y medianos productores que utilizaba fundamentalmente la fuerza de trabajo familiar para la explotación de sus par-

18 López de Albornoz, Cristina: "El derecho a las tierras ... “y " Naturales', 'bárbaros', 'miserables': el discurso liberal y el trato a los pueblos aborígenes tucumanos en las primeras décadas del siglo XIX”, en Actas del 1 Congreso de Investigación Social, Tucumán, 1996, págs. 412-419.

19 Las prácticas que se aplicaban respecto a los derechos de propiedad no son fáciles de comprobar. Mediante los datos cruzados de los apellidos de familias de la comunidad y su condición de originario o forastero que se consignaron en las diferentes visitas efectuadas por las autoridades borbónicas, de los matrimonios consignados en los archivos parroquiales y algunos expedientes judiciales por pleitos de tierras hemos podido observar cómo se desarrollaron estas prácticas en el interior de la comunidad de Colalao y Tolombón. Algunas aproximaciones ya se habían expuesto en el trabajo de López de Albornoz, Cristina, y Bascary, Ana María: "Pueblos indios de Colalao y Tolombón: identidad colectiva y articulación étnica y social”, en Humanitas, núm. 26, Tucumán, 1997, págs. 21-34. 
celas. La diferencia con los campesinos de otras etnias estaba relacionada con sus patrones culturales y el estigma con el que la sociedad colonial los había condenado por ser de la "casta tributaria". ${ }^{20}$

\section{La familia y la tierra: derechos de abolengo y prácticas sucesorias}

Todos los propietarios de tierras, sin distinción, implementaron algún tipo de estrategia para evitar la dispersión de los patrimonios inmobiliarios. Lamentablemente no en todos los casos es posible profundizar en ellas. Es especialmente en el conjunto del grupo constituido por los propietarios de la élite local donde se pueden observar mejor estos mecanismos.

Ya mencionamos que la principal causa que afectaba a los patrimonios de los particulares eran las leyes castellanas sobre la herencia y la ausencia de mayorazgos. De acuerdo a las disposiciones legales, los bienes acumulados por una persona a lo largo de su vida debían ser repartidos equitativamente entre sus descendientes. Las condiciones variaban según se tratara de bienes gananciales, dotes, arras o capitales anteriores a los matrimonios y de acuerdo a la filiación de los deudos (cónyuges, hijos, hermanos, nietos, padres, sobrinos).

Por imposición también del derecho castellano, los bienes de un matrimonio se consideraban gananciales, es decir que se repartían en partes iguales entre el marido y su mujer. Cualquier capital introducido antes (herencias, dotes, patrimonios, arras) quedaba exento de partición y volvía al cónyuge supérstite. Lo que restaba de la división de los bienes gananciales debía repartirse a partes iguales entre los hijos legítimos y reconocidos. ${ }^{21}$

20 Hacia fines del siglo XIX el estigma no había desaparecido aún de las mentes de nuestros esclarecidos legisladores. Es significativo el comentario vertido por Lucio V. Mansilla en la Cámara de Diputados en 1885: "un indio es un indio, y que, sean cuales sean las razones que tuvieron nuestros padres y los legisladores para declarar que son argentinos todos los que nacen en el territorio de la República, no podemos equiparar el indio a los demás habitantes". Diario de Sesiones de la Cámara de Diputados de la Nación, Buenos Aires, 1885.

21 El papel fiscalizador y legitimador de la Iglesia en materia de descendencia, derecho a la herencia y dispensas matrimoniales, se materializó en el registro de la filiación mediante la cual se calificaba a los fieles. Por ello en la documentación de la Iglesia se insistió permanentemente en la división entre los españoles, asociados con los linajes y la legitimidad de los ascendientes, y los "naturales" (donde se incorporó genéricamente al grupo de indios, negros y castas) asociados con la imposibilidad de rastrear los antepasados y la inseguridad de la legitimidad de la prole. Zacca, Isabel: "Una aproximación al estudio de la sociedad colonial. El caso de la construcción de identidades sociales en Salta a fines del período colonial", en Ricardo Cicerchia (comp.): Formas familiares, procesos históricos y cambio social en la América Latina, Quito, 1998, págs. 59-79. 
Desde el punto de vista de la normativa, sólo con el "quinto" (y quizás el tercio) sobre el total de las tasaciones se podía mejorar a algún heredero. En el caso de mediar una partición judicial, la voluntad testamentaria se respetaba siempre y cuando no lesionara los derechos de alguno de los deudos. En esos casos se procedía a inventariar los bienes, se hacían tasar por personas idóneas, se estipulaban los gastos de entierros y costos del juicio para restarlos del conjunto y se descontaban las deudas contraídas por el o la titular. Finalmente, se procedía a definir el monto y la composición de las hijuelas correspondientes a cada heredero.

Pero como ya hemos visto, el peso de las prácticas se impuso sobre la ley, por lo que la transmisión del patrimonio fue más bien el resultado de una sucesión de transacciones y estrategias implementadas por las familias para evitar la dispersión. El mecanismo más frecuente fue la distribución y composición diferenciada de las hijuelas, en las que la tierra solía quedar en manos de algún heredero privilegiado. Si bien el monto total de los bienes solía reflejar el reparto equitativo entre cada uno de los deudos, la distribución de los bienes era el resultado de los arreglos familiares En muchos casos los acuerdos no fueron tales y generaron largos pleitos ante la justicia.

A partir de una muestra de 93 inventarios analizados, entre los cuales 49 consignan el destino de las propiedades rurales registradas en las hijuelas, ha sido posible establecer una tendencia vinculada al reparto de los inmuebles. Si bien no existió una única modalidad en la división de los bienes, en la mayoría de los casos la propiedad inmueble permaneció en manos de los cónyuges (19 casos), especialmente si quedaban hijos menores o se destinaba para el mantenimiento personal. En 24 particiones de tierras, 10 se adjudicaron a los hijos varones, 6 a las hijas mujeres y en los 8 casos restantes se repartieron en forma proporcional. En cuatro ocasiones los inmuebles se mantuvieron expresamente indivisos y en dos más se remataron para pagar las deudas de los difuntos.

Las haciendas, en cambio, fueron repartidas en forma bastante equitativa y muchas veces como adelantos de herencia cuando los hijos contraían matrimonio. La excepción la constituyeron los bueyes, que en cantidades importantes se destinaban al transporte. En ese caso fueron preferidos los hijos varones, así como también fueron preferidos para heredar los establecimientos especiales tales como las tiendas o los cuartos para pulperías, los galpones para carpinterías y los instrumentos de labranza, herrería y para trabajar la madera, las mercancías destinadas a la venta y las carretas. 
Las mujeres por principio y derecho no estuvieron excluidas en las herencias sobre la tierra y las haciendas e incluso, las opiniones de los contemporáneos eran proclives a que ellas administraran los bienes heredados. ${ }^{22}$ La mujer no sólo era considerada absolutamente capaz de encarar el cuidado de los establecimientos rurales, sino que de hecho lo hacía participando en las tareas de siembra, cuidado de animales, fabricación de textiles y pellones. Pero, por otro lado, el rol de la mujer era de fundamental importancia en la transmisión patrimonial por su condición de heredera y portadora de la "dote", que muchas veces incluía la tierra. Las dotes compuestas por inmuebles fueron el estímulo para concertar las alianzas matrimoniales que consolidaron las redes entre familias, especialmente de la elite. ${ }^{23}$ Esto consolidó el prestigio de un reducido número de patronímicos locales creando, de este modo, solidaridades basadas en el parentesco y la afinidad. Los casamientos entre primos permitieron consolidar los patrimonios, preservando la riqueza mancomunada. La tendencia endogámica y hasta incestuosa en algunos casos, contaba con la aprobación de la Iglesia, ya que los impedimentos se sorteaban muy fácilmente con la solicitud de la dispensa matrimonial. ${ }^{24}$ Numerosas razones favorecían el matrimonio entre parientes, pero la principal parece haber sido la necesidad de conservar los patrimonios familiares. El compadrazgo, por otro lado, reforzaba las relaciones de consanguinidad y las vinculaciones relacionadas con los negocios. El parentesco ficticio que creaba el padrinazgo permitía intensificar o ampliar los lazos familiares. Podía establecerse entre parientes consanguíneos como entre personas no emparentadas, aunque para la elección parecen haber existido un cúmulo de motivaciones entre las cuales figuraban la riqueza, el prestigio de una profesión u ocupación, las relaciones

22 En el juicio sucesorio de los bienes de doña Francisca Sueldo, vecina de Leales que había fallecido en 1758, el Juez de Menores reclama la ineptitud del albacea encargado de la administración, disponiendo que se les diera dominio sobre los bienes heredados a las dos hijas solteras que tenía doña Francisca, considerando que "siendo corriente que semejantes personas que habitan en las estancias aunque sean mujeres se esmeran en el cuidado de sus haciendas como dueño propio de ella..." (AHT, Sección Judicial Civil (en adelante SJC), Serie A, Caja 15, expte. 12).

23 A partir de la circulación de las mujeres, mediante la dote y su descendencia, se tejía la abigarrada trama de alianzas de las élites americanas.

24 La legislación canónica que regulaba la celebración de los matrimonios impedía el casamiento entre miembros emparentados en segundo grado de consanguinidad y primero de afinidad, salvo por expresa dispensa papal. Ante las dificultades que involucraba para los habitantes americanos lograr tales dispensas, la Corona autorizó a los arzobispos, obispos e incluso curas párrocos, a otorgarlas para permitir los matrimonios entre primos. Esta medida tuvo siempre un carácter limitado y temporal, aunque fue prorrogada frecuentemente por la Santa Sede. 
hacia fuera de la comunidad y la posibilidad de otorgar un lugar dentro de la sociedad..$^{25}$

Parentesco y proximidad residencial se combinaban, también, como otro de los mecanismos de preservación de los patrimonios. En general ello implicaba compartir los condominios sin proceder a la división efectiva de los inmuebles. La estrategia consistía en explotar en conjunto las tierras heredadas pues en muchos casos la división podía conducir al fracaso de la supervivencia de los hogares. No podemos asegurarlo, pero esta práctica pudo conducir a la inalienabilidad de las propiedades familiares. En los padrones censales y en los expedientes judiciales se han registrado casos donde las familias de parientes vecinos deslindaban derechos y obligaciones diferenciadas entre ellos bajo la cohesión de un jefe o cabeza (masculino o femenino) que permitía armonizar las relaciones familiares y de producción.

Pero también hubo otras figuras previstas por el derecho castellano para la circulación restringida de las propiedades inmuebles, como eran las donaciones "intervivos" o de cláusula testamentaria, y los patrimonios. En el primer caso, la donación implicaba una renuncia "actual e irrevocable" al dominio del bien y se practicaba, generalmente, entre parientes. En el segundo caso, la donación sólo era posible con respecto a los bienes dotales o de herencia de alguno de los cónyuges, pero nunca sobre los bienes gananciales. El patrimonio laical, por otro lado, actuaba como la dote, es decir, como un anticipo de herencia destinado a los hijos o hijas que se ordenaban como sacerdotes o monjas.

Las familias propietarias apelaron también a otras instancias jurídicas previstas por el derecho castellano como eran los derechos de abolengo. ${ }^{26}$ Ellos permitían que los parientes fueran preferidos en las ventas y cesiones de los dominios familiares. Tres figuras fueron reconocidas en la práctica vinculada con la transferencia de inmuebles como derechos de abolengo: el tanteo, el retracto y el régimen capellánico. Mientras este último impedía

25 En el ámbito comprendido por el Río de la Plata y el antiguo Tucumán, los trabajos sobre compadrazgo recién comienzan a conocerse, por lo que es muy difícil hablar de patrones o tendencias respecto a este tipo de relaciones interfamiliares. Por lo pronto, se puede ver Santilli, Daniel: "Algunos apuntes acerca del compadrazgo en Quilmes (1780-1840)", ponencia presentada en las VIII Jornadas Interdepartamentales de Historia, Salta, Argentina, 2001.

26 Este indicador, de fundamental importancia a la hora de analizar la variable de la fragmentación y rotación de tierras en el período colonial, ha sido poco tomado en cuenta por la historiografía, quizás porque la aplicación de estos derechos no siempre quedó registrada públicamente, y sólo es posible descubrirla a partir de un minucioso análisis de seguimiento de traspaso de las propiedades inmuebles. 
relativamente la circulación de los inmuebles, ${ }^{27}$ los dos primeros lo limitaban al ámbito familiar o, cuando mucho, al comunal. ${ }^{28}$ Estos derechos recíprocos condicionaban cualquier tentativa de venta o donación entre miembros ajenos a la familia, e incluso a las órdenes religiosas.

En la práctica las capellanías fundadas en la jurisdicción de Tucumán durante el período analizado estuvieron restringidas mayormente a los inmuebles urbanos, aunque hubo algunas impuestas sobre estancias y tierras rurales. Ello no impidió la transferencia de las propiedades afectadas, aunque en su mayoría se mantuvieron dentro del núcleo familiar.

Respecto de la aplicación del derecho de tanteo y retracto, son muy pocos los casos protocolizados entre las operaciones de compraventa. A modo de ejemplo citamos uno de ellos. Se trata de don Félix de Aragón, vecino del paraje de Los Aragones. En 1789 doña Magdalena Aragón (prima suya y coheredera de las tierras que pertenecieron a su abuelo) vendió su parte a los hermanos Toledo por valor de 60 pesos. Enterado de la transacción, don Félix hizo presentación ante el juez aduciendo que "en virtud del derecho que me da la Ley para que por el hereditario a abolengo pueda oponerme al tanteo lo hago en debida forma haciendo oblación de los sesenta pesos en que fueron vendidas dhas tierras y se cancele el auto de posesión". El recurso de Aragón desencadenó un largo juicio donde se cuestionó el tiempo en que se había interpuesto el derecho (que según los oponentes había superado el plazo legal) y hasta la relación de consangui-

27 La definición más amplia sobre capellanía es la que la describe como: "fundación, instituida generalmente a perpetuidad, por vía testamentaria o por acto entre vivos, en virtud de la cual el fundador afectaba un bien inmueble, o una suma de dinero situada sobre un inmueble, para costear con sus rentas la celebración de misas y otros actos píos, y beneficiar a determinadas personas o instituciones: a título de patrimonio si esas personas aspiraban al sacerdocio, o al mero título de patronos y capellanes. La escritura de fundación era el estatuto particular de cada capellanía". Levaggi, Abelardo: Las capellanías en la Argentina. Estudio Histórico-jurídico, Buenos Aires, 1992, págs. 21-23.

28 El tanteo era "el derecho que por ley, costumbre o convenio se otorga a una persona para adquirir algo con preferencia a otro y por el mismo precio en caso de enajenación a título lucrativo. El retracto, en cambio, era "la acción por la cual un tercero (retrayente) es autorizado por la ley en ciertos casos, para que sustituya al adquiriente de un bien o conjunto de bienes (el retractado), con el fin de apropiarse así del beneficio y carga consiguiente a esa adquisición, en lugar del adquiriente primitivo a quien sólo está obligado a indemnizar sus gastos y desembolsos. De Santos, Víctor (director), Diccionario de Ciencias Jurídicas, Políticas, Sociales y Económicas, Buenos Aires, 1996. En la antigua legislación hispanoamericana, era el derecho establecido en favor de los parientes colaterales (hasta cuarto grado) para que, en el caso de venta de algún bien familiar, pudieran exigir la anulación de la operación, y ser preferidos. Este derecho, conocido también como retracto de abolengo, podía ejercerse hasta nueve días después de efectuada la venta. Pero también se reconocen, aunque en nuestro territorio no hemos localizado ningún caso, el retracto de comuneros y de superficiarios (condóminos y dueños, respectivamente). 
nidad que le asistía al demandante. Finalmente el juez falló a favor del interesado por lo que doña Magdalena debió retractarse de la operación. ${ }^{29}$

Para concluir podemos decir que las familias propietarias apelaron a diferentes estrategias que les permitieran eludir las disposiciones impuestas por el derecho castellano respecto a la herencia y la transferencia de la tierra. De ese modo pudieron evitar, en algunos casos, la dispersión de los patrimonios familiares. Unas pocas tuvieron éxito y conservaron (e incluso acrecentaron) sus propiedades inmuebles. Los más claros ejemplos fueron los de las familias encabezadas por Miguel Antonio de Alurralde, Roque Ávila, los hermanos Martín León y José Gabriel García, Juan Luis Ibiri, José Molina, el cura Ignacio Norri, Julián Ruiz de Huidobro, los hermanos Miguel Gerónimo y Francisco Sánchez de La Madrid, entre otras muchas. Otras, no pudieron sortear los problemas que acarreaban las particiones de los inmuebles por el peso de las herencias y la historia familiar y perdieron gran parte de sus bienes.

\section{Fraccionamiento y acumulación}

Desde 1750 en adelante hay una consolidación del fenómeno de fragmentación de las propiedades heredadas, donadas, vendidas y/o cedidas, con la evidente demanda creciente de tierras. Ello puede observarse a partir de las medidas tomadas por el Estado mismo y en las operaciones inmobiliarias efectuadas más allá de los vínculos familiares directos.

Como ya hemos planteado, el fraccionamiento de la propiedad inmueble fue, en parte, el resultado directo de la aplicación del derecho castellano y la ausencia de mayorazgos, por lo que los bienes quedaban sujetos a la partición equitativa entre todos los descendientes reconocidos. Pero es importante reconocer también que las diferentes coyunturas económicas de los siglos XVII y XVIII incidieron igualmente en la fragmentación y posterior venta de los inmuebles. Es cierto que en algunos casos las propiedades permanecieron "indivisas" por largo tiempo, incluso por varias generaciones. Pero no todos los grupos propietarios pudieron conservar sus inmuebles y ello se puede constatar a partir del origen de los inmuebles mercantilizados desde la segunda mitad del siglo XVIII: el $49 \%$ de las tierras vendidas procedían de herencias en segunda y tercera generación, el $24 \%$ correspondía a

29 AHT, SJC, Serie A, Caja 36, expte 5, 23 de julio de 1789. Autos sobre unas tierras en el paraje de "Aragones". 
tierras anteriormente compradas por los vendedores, y un 4,5\% estaba constituido por las tierras donadas, cedidas como patrimonio u obtenidas por cobro de derechos parroquiales y algún tipo de gravamen sobre la propiedad.

Es evidente que buena parte de la tierra que entró en circulación a partir de la segunda mitad del siglo XVIII procedía de las antiguas propiedades familiares. En general, estas estancias o potreros eran vendidas por los herederos en parcelas y fracciones del bien común.

Entre las propiedades más fragmentadas durante este período se registraron la estancia del Manantial, que había pertenecido a la familia Silva y estaba ubicada en el curato Rectoral; las estancias del Cercado de la familia Núñez; la de Pueblo Viejo, de los Artázar y la estancia de San Gerónimo, de Román Pastene, en el curato de Monteros; la estancia de Mancopa de la familia Robles, en Los Juárez; los potreros de Anfama y La Ciénaga; los potreros de Medinas y la estancia del Timbó en Burruyacu, y en el curato de Choromoros las estancias de El Asequión, Los Planchones y El Tala, junto con los potreros de Yarame y Nocto, de los Alurralde.

Las tierras de Mancopa habían pertenecido durante décadas a una única familia: los Robles, cuyo tronco familiar se inició con la llegada del sargento mayor don Diego de Robles, teniente tesorero de la Real Caja de Tucumán y que al poco tiempo contrajo matrimonio con doña Úrsula Bautista Palavecino. No podemos saber exactamente qué aportó cada uno de los cónyuges en la sociedad conyugal porque no se han conservado sus testamentos. Sí sabemos, por los legados de sus hijos, que ambos dejaron en herencia tierras "en la otra banda", que incluía el paraje de Mancopa y sus inmediaciones hasta Leales. ${ }^{30} \mathrm{~A}$ juzgar por las sucesivas "suertes" que se fueron vendiendo a lo largo de más de dos décadas, la extensión de la propiedad debió haber superado las dos leguas cuadradas. La herencia tuvo que repartirse entre seis hermanos (tres varones y tres mujeres), aunque de hecho el conjunto de la propiedad recayó en los tres varones. ${ }^{31}$ La venta de las tierras fue iniciada por

30 Las tierras de Leales habrían sido originalmente de los Palavecino. En 1774, doña María Rosa Robles, viuda de Mateo Bautista Palavecino, a su vez descendiente en cuarta generación de don Diego de Robles, inició pleito por unas tierras de la estancia de Leales a doña María Palavecino, viuda de Juan Leal de Medina. Las tierras de Leales, según este expediente, pertenecían a don José Bautista Palavecino, padre de don Mateo, y no tenía herederos forzosos más que su hijo. El problema surgió cuando don José, que había criado a la huérfana María "como a su hija", decidió donarle la mitad de la estancia, generando, a la muerte de Mateo, el pleito por los derechos sucesorios. AHT, SJC. Serie A, Caja 25, expte. 24.

31 Sostenemos esta suposición avalada por los testamentos e inventarios de los bienes de las hijas mujeres, que en ningún caso mencionan inmuebles rurales, pero sí casas en la ciudad, esclavos, ajuar, muebles. AHT, SJC, Serie A, Caja 20, expte.30, Testamento de María Francisca Robles, 1765; y Caja 20, expte. 11, Pleito por herencia de Isabel Robles, 1770. 
una nieta de don Diego (María Juana), a su vez hija de don Diego (h), quien en menos de un año vendió tres suertes de tierras. ${ }^{32}$ doña María Juana había enviudado de José Pedraza y quedó con muchos hijos. Algunos de ellos eran menores de edad y el resto, mujeres en edad de matrimonio, es decir, pasibles de dote. Logró casar a una de ellas con un tío hermano suyo - previa dispensa matrimonial del obispo- y el apellido Robles volvió a regir entre sus descendientes (cinco mujeres y un varón). ${ }^{33}$ En el interín, las hermanas Javiera y Ana María Pedraza, hijas de María Juana, vendieron sus partes indivisas. ${ }^{34} \mathrm{Su}$ prima Juana, hija de Francisco Robles, se casó con un vecino de Catamarca y también vendió su parte de tierras. ${ }^{35}$ Finalmente María Antonia y María Dolores Robles, hermanas y nietas de María Juana Robles, hijas de Antonia Pedraza, vendieron también sus parcelas ${ }^{36}$ (gráfico 1).

A través de este caso puntual es posible analizar las prácticas implementadas por algunas familias respecto del patrimonio inmobiliario, a la vez que observar la incidencia de las coyunturas económicas y las historias personales y familiares en el fomento de tales prácticas. Así es como, en un intento por preservar el patrimonio indiviso, vemos a las mujeres de la primera generación de la familia Robles excluidas de la herencia de las tierras rurales. A partir de la segunda y hasta la cuarta generación, la dispersión patrimonial se produjo a través de las descendientes femeninas, en este caso reconocidas como herederas en igualdad de condiciones con sus hermanos varones, las que, por una u otra causa, terminaron vendiendo sus parcelas. Los hombres mantuvieron parte de la herencia hasta casi fines del 90, cuando algunos de ellos comenzaron a disponer su venta. ${ }^{37}$ Sólo Javier Robles, dedicado al negocio de los transportes, se quedó definitivamente con la propiedad que le pertenecía, la que destinó a la cría de los bueyes utilizados para el tiro de las carretas y algunas otras haciendas. Finalmente asoció a su hijo Gervasio y a su yerno Eduardo Sosa en la compañía carretera, destacándose como uno de los principales fleteros de la región. ${ }^{38} \mathrm{El}$ apellido Robles fue desapareciendo con el tiempo, como consecuencia de la muerte prematura de muchos de los varones de la familia y el predominio de las mujeres en casi todas las generaciones.

32 AHT, SP, SA, vol. 7, fs. 141-143 del año 1773, fs. 84-86 y 112v.-114v. del año 1774.

33 Corominas, Jorge: Matrimonios de la Catedral de Tucumán, 1727-1765, en Fuentes Históricas y Genealógicas Argentinas, núm. 20, acta núm. 66, Buenos Aires, 1987.

34 AHT, SP, SA, vol. 8, fs. 75v.-77v. del año 1777 y fs. 20-21 del año 1781.

35 Ibídem, vol. 9, fs. 104-106 del año 1783.

36 Ibídem, vol. 9, fs. 19v-20 del año 1784.

37 Ibídem, vol. 9, fs. 104-106 del año 1783.

38 López de Albornoz, Cristina: "Arrieros y carreteros tucumanos. Su rol en la articulación regional (1786-1810)", en Andes, núm. 6, Salta, 1994, págs. 89-122. 
CRISTINA LÓPEZ DE ALBORNOZ

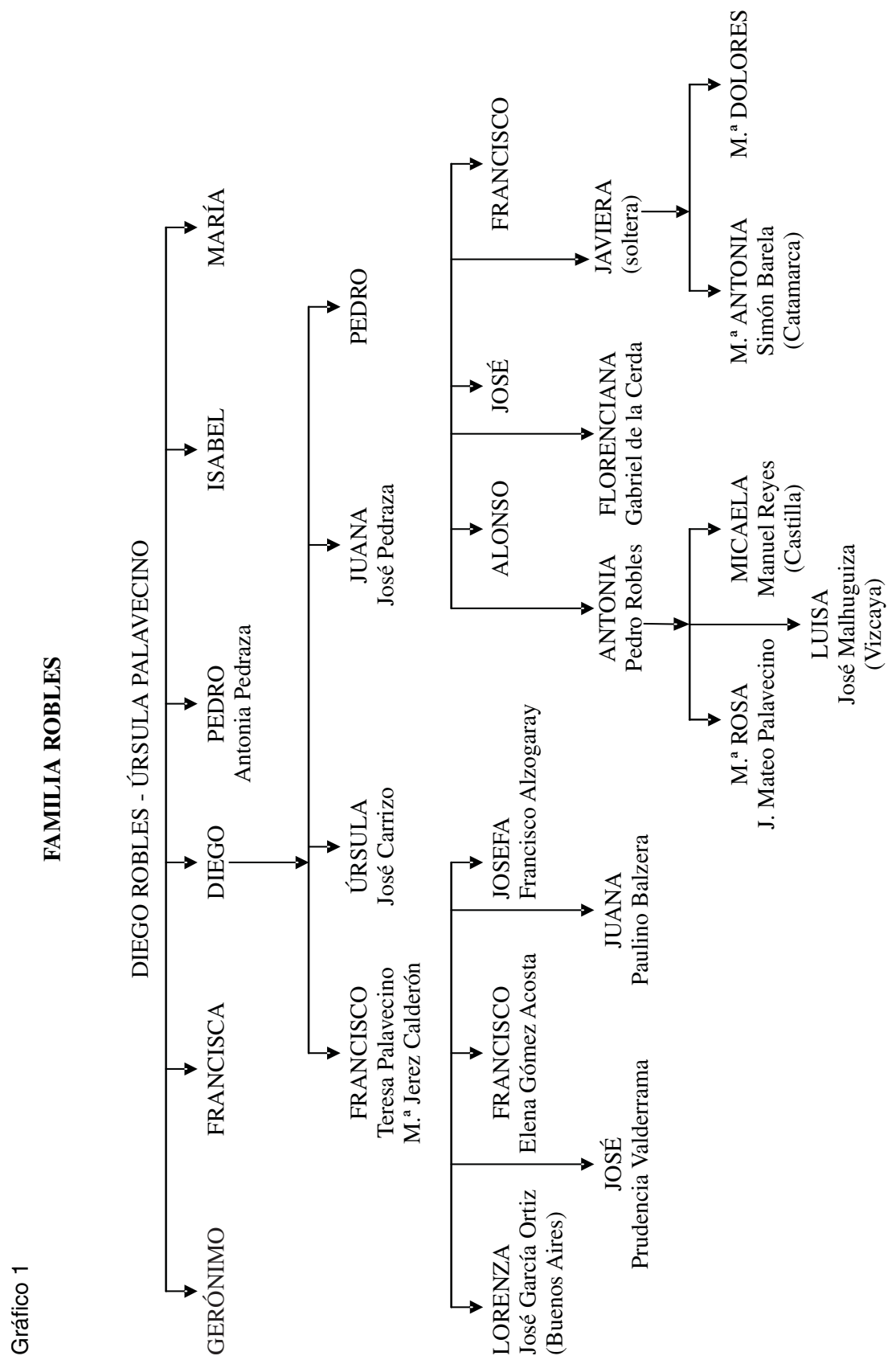

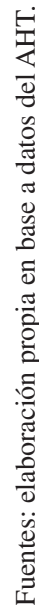


Otro ejemplo ilustrativo de la fragmentación de los bienes patrimoniales es el que se refiere al destino de las tierras conocidas como Estancia El Cercado, pertenecientes durante dos generaciones a la familia Núñez. El capitán Julián Núñez compró en 1754 a la Compañía de Jesús la Estancia de El Cercado, ubicada en el curato de Monteros y evaluada en 450 pesos. $\mathrm{Al}$ poco tiempo vendió parte de su propiedad al cura Ignacio Norri. En la década del 70 sus herederos hicieron lo propio con el resto. Su hijo Luis vendió la mitad de su herencia al mismo cura Norri. Al año siguiente, su hermano Bernabé transfirió todos sus derechos a Ignacio Alderete. Las hijas mujeres continuaron con las ventas. Doña Valentina, casada con Isidro Aldonate, vendió una fracción en 1780 a Ignacio Alderete y otra en 1795 a Francisco Burgos y Catalina, esposa de Juan Bautista Iturrios, vendió dos fracciones de su herencia en 1784 a Francisco Burgos y a José Ladrón de Guevara. El primero adquiriría luego otra parcela de Valentina. El fraccionamiento no terminó allí, pues algunos de los terrenos comprados por los nuevos dueños fueron vendidos o cedidos, una vez más, antes de 1800. Es el caso de la fracción adquirida por el cura Norri, donada a su cuñado, Santiago Paz, quien a su vez, en 1793, vendió una parte a Dionisio López y Bruno Alderete, quienes ya contaban con tierras linderas, como se puede observar en el gráfico 2.

De este ejemplo es posible extraer varias conclusiones. Por un lado, es evidente el excesivo fraccionamiento que fueron sufriendo las propiedades familiares. Por otro lado, es importante notar la velocidad con la que "rotaron" las tierras en apenas cuatro décadas (cuatro veces en la mayoría de los casos y seis en la fracción comprada por el cura Norri), lo que indica una crónica inestabilidad dominial, a pesar de los intentos por preservar los patrimonios. Finalmente, también es posible observar un proceso de compra de varias parcelas por parte de los mismos personajes, en un claro intento por concentrar algunas extensiones mayores de tierras. Las parcelaciones en algunos casos llegaron a extremos que dejaron reducidas las propiedades a unas pocas varas cuadradas.

Un comentario especial merecen las tierras de Lules. Éstas habían pertenecido, hasta 1767, a la Compañía de Jesús y conformaban parte del complejo jesuítico en el que la Hacienda homónima desempeñaba un papel central en la producción y mantenimiento del Colegio de San Miguel de Tucumán. Se extendía sobre las "tierras bajas", según se diferenciaban los inmuebles de los expulsos, desde el sur de las tierras del Manantial (que pertenecía a Ignacio Silva) y entre el río Lules y el arroyo de la Reducción. 
Su extensión, sumando las tierras de la hacienda, la estancia y aledaños rondaba las 6 leguas de frente y 8 de fondo. En el momento del remate de las propiedades de las Temporalidades (1774), las tierras de Lules y La Reducción fueron parceladas para ser vendidas

"entre los labradores pobres, según se dispone por su Magestad en sus reales colecciones con la condición de que mientras lo redime haia de poner por especial ypoteca para el seguro de su principal, que se le dan a venta en censo"..$^{39}$

En aquella oportunidad se vendieron 24 parcelas a censo redimible cuyas extensiones eran de $1 / 4$ de legua de frente con todo su fondo hasta las aguadas. Pero a partir del mismo año de 1774 varias propiedades fueron transferidas con sus censos por los compradores originales. A partir de 1780 las parcelas redimidas entraron al mercado inmobiliario, produciendo en algunos casos una mayor fragmentación y en otros la acumulación de varias parcelas.

\section{CuAdro 2 \\ FRACCIONAMIENTO Y RECOMPOSICIÓN DE ALGUNAS ESTANCIAS VENDIDAS ENTRE 1760 Y 1810}

\begin{tabular}{lccc} 
& fracciones & compradores & reventas\# \\
\hline Estancia de Amaicha & 6 & 6 & \\
Potrero de Anfama & 4 & 3 & 1 \\
Tierras de Choromoros & 4 & 4 & 2 \\
Estancia El Asequión & 4 & 4 & 1 \\
Estancia El Cercado & 7 & 5 & \\
Tierras del Manantial & 15 & $10(*)$ & 1 \\
El Potrerillo & 9 & 7 & 1 \\
Estancia El Timbó & 11 & $6(* *)$ & \\
Estancia San Gerónimo & 5 & 4 & \\
Estancia Los Planchones & 2 & 1 & \\
Tierras de Mancopa & 11 & 8 & \\
Estancia de Manchalá & 5 & 3 & \\
Potrero de Riquelme & 3 & $2(* * *)$ &
\end{tabular}

\# se incluyen las ventas efectuadas por alguno de los que operaron como compradores o sus descendientes (*) cuatro parcelas son compradas por el cura Ignacio Norry

(**) seis parcelas son compradas por don Juan Luis Ibiry

(***) las dos terceras partes del Potrero son compradas por don Pedro Lobo

Fuente: AHT, Protocolos Notariales, 1760-1810

39 López de Albornoz, Cristina: "La sociedad de San Miguel de Tucumán en la primera mitad del siglo XVIII", en La ocupación del espacio de San Miguel de Tucumán y su jurisdicción. 1700-1750, Tucumán, 1994, págs. 25-55. 


\section{GRÁFICO 2}

\section{CASOS DE ROTACIÓN DE LA PROPIEDAD DE LA TIERRA}

Figura 1

\section{Estancia El Cercado}

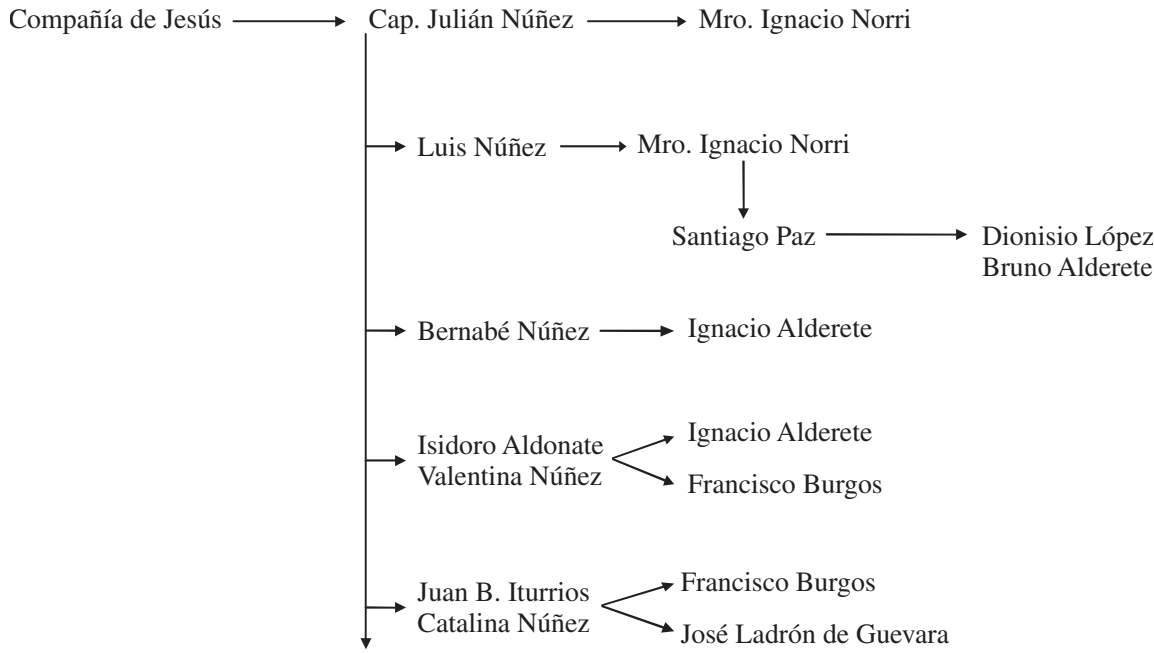

Figura 2

Estancia de AMAicha (MONTEROS)

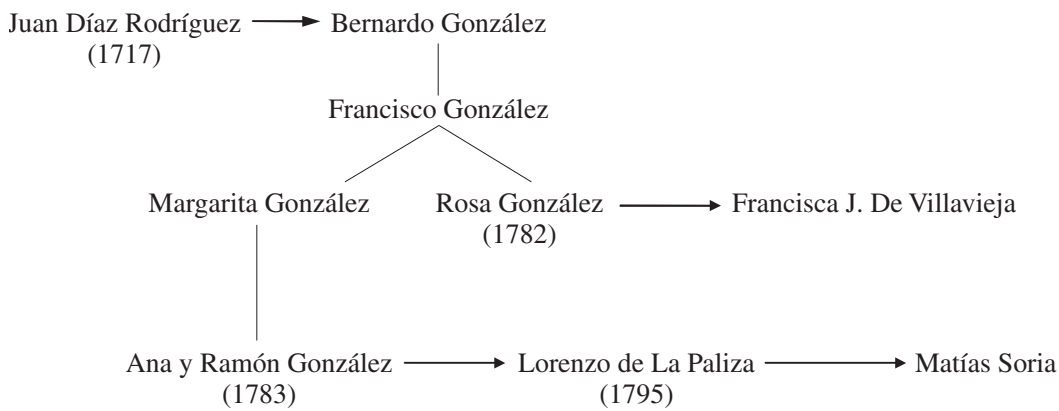

Fuentes: Elaboración propia sobre datos del AHT. 
En la mayoría de los casos citados el fraccionamiento fue muy marcado y en lo que respecta a la adquisición de varias parcelas por un solo comprador nunca alcanzaron a superar la mitad de la extensión original. Pero aquí es importante insistir en dos aspectos que no pueden quedar sin comentarios por un lado, se debe reconocer que la adquisición por compra no fue el único mecanismo de acumulación de tierras sino más bien el recurso menos utilizado por los grupos de poder, aunque el privilegiado por los sectores medios, los recién llegados, los nuevos "vecinos"; y por otro lado, es necesario destacar que las familias propietarias, aunque no lograban recomponer las antiguas extensiones de potreros y estancias, solían reunir importantes patrimonios, generalmente dispersos por toda la campaña de Tucumán.

\section{El arrendamiento y otras formas de tenencia}

Hemos observado que si bien es bastante difícil reconstruir la estructura de la propiedad y tenencia de la tierra en Tucumán porque las referencias documentales acerca de las mercedes de inmuebles son escasas, los datos que han quedado sobre ellas nos permiten analizar cómo se produjo el fraccionamiento y eventual acumulación de tierras rurales, a la vez se pudo observar, mediante las compraventas, el avance de la frontera de ocupación de las tierras y posterior apropiación legal. ${ }^{40}$

Por otro lado, también hemos constatado que un alto porcentaje de "criadores" y "estancieros" del siglo XVIII no contaba con la propiedad de la tierra, pero ya hemos adelantado que el sistema colonial se fundaba en prácticas de acceso a un inmueble rural que no pasaban necesariamente por el régimen de propiedad. Y uno de ellos fue el arrendamiento.

En la región pampeana, donde esta forma de acceso a la tierra ha sido mejor analizada, se ha comprobado que tal institución rural, sumada a otras como la aparcería y la medianería, estuvo íntimamente asociada con la transformación agraria y la expansión de la producción agrícola y ganadera de fines del siglo XVIII y el siglo XIX. Ellas se mantuvieron, ante la ausencia de una legislación específica, regidas por los usos y las costumbres. ${ }^{41}$ Este sector de productores rurales que parece no haber estado exten-

40 Como fuente documental las mercedes de tierras y encomiendas que se han conservado en el AHT para el siglo XVI, suman poco más de dos decenas, mientras que en el siglo XVII, cuando se establece el requisito de la "confirmación real" de los títulos de propiedad, su número se duplica. Ver López de Albornoz, Cristina: "El derecho a las tierras ..." 
dido en forma dominante en las regiones del Virreinato del Plata, tampoco puede considerarse como un "fenómeno residual". Los censos del período no registran su presencia, aunque a juzgar por los expedientes judiciales, una parte importante de la población rural usufructuaba la tierra bajo esa forma de tenencia. De acuerdo a la contribución de habitantes del curato de Burruyacu correspondiente al año 1812, el porcentaje de arrendatarios de esa región alcanzaba al 34\%, mientras que el de propietarios sólo llegaba al $13 \%$. El resto de la población usufructuaba la tierra sin derechos legales claros. ${ }^{42}$ Por lo pronto no hemos podido confirmar en qué medida este sistema estuvo extendido en otros curatos de la campaña, o si en el caso de Burruyacu, como curato de frontera, el arrendamiento era el reflejo del modelo de expansión agrícola en el contexto de grandes extensiones que habían comenzado a ser explotadas desde las últimas décadas del siglo XVIII. A través de algunos expedientes judiciales hemos podido constatar la presencia de arrendatarios en otros ecosistemas de la campaña, pero al tratarse de casos aislados no podemos mensurar el alcance de esta práctica. ${ }^{43}$

Remontándonos atrás en el tiempo, el arriendo parece haber constituido la forma de organizar la explotación de las tierras que habían pertenecido a la Compañía de Jesús. ${ }^{44}$ Ya comentamos que el alto grado de autosuficiencia de los establecimientos rurales de algunas órdenes religiosas como la de los jesuitas, respondía a pautas generales de racionalización para obtener mano de obra y manejar grandes volúmenes de producción. La ganadería constituía la producción dominante, caracterizada por la invernada de mulas y la cría de vacunos y bueyes. Estas actividades se complementaban con la agricultura de maíz, trigo, frutales y algunos cañaverales. El resto de la producción incluía fabricación de muebles, carretas, toneles, quesos, suelas y lomillos. El trabajo en las estancias involucraba mano de obra indígena, esclavos y peones conchabados. Pero numerosas familias campesinas se establecieron en las propiedades jesuitas en calidad de agregados y arrendatarios, participando de la producción para sí y para la

41 Fradkin, Raúl: "La historia agraria y los estudios de establecimientos productivos en Hispanoamérica colonial: una mirada desde el Río de la Plata", en Fradkin, R. (comp.): La historia agraria del Rio de la Plata colonial. Los establecimientos productivos, núm. 1, págs. 7-44, CEAL, Los Fundamentos de las Ciencias del Hombre, núm. 114, Buenos Aires, 1994.

42 López de Albornoz, Cristina: "Vivir y trabajar... "

43 En nuestro trabajo de Tesis de Maestría (cit. en nota 9) hemos podido rastrear algunos casos de arrendatarios pero su número es muy exiguo. Apenas llegan a cuatro.

44 El "modelo jesuítico" en toda Hispanoamérica incluía la presencia abundante de arrendatarios en las tierras de sus establecimientos 
Compañía. ${ }^{45}$ Las prestaciones personales de los agregados incluían todas las tareas de las haciendas: arar, sembrar, cosechar, recoger ganado, participar de la yerra, llevar a cabo los "apartes" y la reparación de cercos.

Durante la administración de la Junta de las Temporalidades algunos inmuebles siguieron arrendados, respondiendo a la continuidad de los contratos iniciados con la Orden. A la vez, se dispusieron nuevos arriendos que beneficiaron a los miembros de la Junta y sus parientes. Como resultado de la primera disposición relacionada con la enajenación de los inmuebles, sólo se arrendaron "las tierras de Vipos" al maestre de Campo don José de Figueroa. Este establecimiento incluía cinco leguas cuadradas, en gran parte "bajo riego", con las cepas y herramientas necesarias para su laboreo y seis fanegas de trigo para semillas. Fue arrendado por el monto de 20 fanegas de trigo anuales. ${ }^{46} \mathrm{El}$ caso resulta de particular singularidad porque los registros posteriores sobre arriendos de tierras de las Temporalidades fijaron montos menores por este concepto (entre 5 y 10 pesos anuales). Tales fueron los cánones aplicados por el concepto de arriendo de 15 parcelas pertenecientes a la Compañía, entre las que se encontraban algunas de las "suertes de tierras" de la estancia de Lules y otras del Taficito. El arriendo de Vipos duró muy poco tiempo, porque entre 1771 y 1774 la hacienda ya estaba atendida por personal conchabado por la Junta que se encargaba del cuidado y manutención de las haciendas ganaderas que se hacían pastar allí.

La extensión temporal y la falta de pagos de los cánones determinó finalmente la venta de los inmuebles. Muchos de los arrendatarios se convirtieron en propietarios de las mismas parcelas, aunque otros perdieron en las posturas y debieron trasladar sus haciendas y abandonar las mejoras. Ello ocurrió con el potrero de Raco, arrendado por don Fermín de Paz por 50 pesos, quien no pudo acceder a su compra durante los remates de los inmuebles.

Otro potrero arrendado antes de su venta fue el de San Javier. La operación se efectuó en junio de 1772 por el monto de 20 pesos anuales y el arrendatario fue don Juan Quintero, quien estuvo autorizado para poblarlo con sus mulas. Algunos de esos arrendamientos no fueron avalados por la Junta sino por los administradores de turno, como ocurrió con el potrero de

45 López de Albornoz, Cristina: "Incidencia de la venta de los inmuebles..."; Mayo, Carlos, y Giménez, Fernando: "La estancia de San Ignacio en la gobernación de Tucumán (1767-1768)", en Mayo, Carlos (comp.): La historia agraria del interior. Haciendas jesuíticas de Córdoba y el noroeste, Buenos Aires, 1994, págs. 37-51.

46 El precio de la fanega de trigo fue fijado en seis pesos por el Cabildo en la década del $80 \mathrm{y}$ se mantuvo constante hasta comienzos de la Revolución. 
Las Tipas, ocupado por don Martín Ángel Varón, quien recibió la autorización de don Rafael de Hoyos, administrador de las Temporalidades hasta 1771. En setiembre de 1772, los miembros de la Junta exigieron el desalojo del "intruso" y sus haciendas, por lo que debió pagar el canon correspondiente a los años que lo ocupó. ${ }^{47}$

\section{CUADRO 3}

\section{ARRENDATARIOS DE TIERRAS DE LAS TEMPORALIDADES}

\begin{tabular}{lccc} 
Arrendatario & Tipo & Ubicación & Canon \\
\hline Cap. José Orellana & suerte de ts. & Lules & $10 \mathrm{ps}$ \\
Pasqual Díaz & suerte de ts. & Lules & $10 \mathrm{ps}$ \\
Bernardina Leal & $3 / 4$ leguas & San Pablo & $8 \mathrm{ps}$ \\
Juan José Zeballos & suerte de ts. & San Pablo & $5 \mathrm{ps}$ \\
Joaquín Monzón & suerte de ts. & Lules & $5 \mathrm{ps}$ \\
José Drago & suerte de ts. & R. Colorado & $5 \mathrm{ps}$ \\
Luis Caldes & suerte de ts. & Lules & $5 \mathrm{ps}$ \\
Francisco Moreno & suerte de ts. & Yerba Buena & $\mathrm{s} / \mathrm{d}$ \\
José Ferreyra Carnero & suerte de ts. & Lules & $5 \mathrm{ps}$ \\
Juan de Indarte & suerte de ts. & Potr. Grande & $\mathrm{s} / \mathrm{d}$ \\
Juan B. Iturrios & suerte de ts. & Lules & $5 \mathrm{ps}$ \\
Alejandro Ríos & suerte de ts. & Lules & $\mathrm{s} / \mathrm{d}$ \\
Juan López Ríos & suerte de ts. & Marlopa & $5 \mathrm{ps}$ \\
Pedro José Mena & suerte de ts. & Taficillo & $\mathrm{s} / \mathrm{d}$
\end{tabular}

Fuente: elaboración propia sobre datos del AHT, SA y SP.

\section{El sistema}

El sistema de arriendos difundido en los establecimientos jesuitas fue incorporado por otros sectores de la sociedad tucumana, entre ellos algunos particulares y los pueblos de indios. La práctica parece haber tenido una importancia singular para el ingreso en metálico y especies y probablemente, aunque no lo podemos asegurar, para la provisión de mano de obra estacional. Por otro lado, la presencia de arrendatarios en la campaña tucumana, estuvo asociada tanto con la explotación agrícola como con la ganadera. No podemos asegurar en qué momento y con qué intensidad se produjo su expansión, pero los casos puntuales son ilustrativos

47 AHT, SJC, Serie A, Caja 27, expte. 8. 
Hemos podido constatar que la comunidad indígena de Colalao y Tolombón, cuyas tierras se ubicaban en el valle de Choromoros (Trancas), arrendaba parcelas a "forasteros". ${ }^{48}$ En 1804, ocho de ellos reconocían a los indios de Colalao y Tolombón como dueños de las tierras que ocupaban. ${ }^{49}$ Las tierras arrendadas se ubicaban en la región más rica en pastizales, en el paraje de La Ciénaga, La Toma, el Río Chuscha y el Sauzal y se pagaban 8 pesos de plata anuales por una parcela. A mediados del siglo XIX el sistema de arriendos seguía vigente: en 1830 se recaudaban 200 pesos anuales por este concepto y, teóricamente al menos, pasaban a formar parte de la caja de comunidad. ${ }^{50}$ En 1832 había 54 arrenderos, de los cuales el 50\% pagaba un canon de 2 pesos anuales y el resto oscilaba entre los 3 y los 6 pesos. Sólo uno de ellos, don José Gabriel Dávila, pagaba 50 pesos. ${ }^{51}$ Los ingresos obtenidos por este medio y otras fuentes de producción debían ser repartidos entre los integrantes de la comunidad. Sin embargo, en 1832 el gobernador Heredia denunció a Valentín Senardo y a Pedro Goya (indios originarios del pueblo) por haberse apropiado de los arriendos y no haberlos distribuido entre los propietarios. La acusación era muy interesada pues Heredia fue uno de los vecinos más comprometidos en los litigios por la propiedad de la comunidad india.

¿Qué ocurrió en las estancias particulares? Aparentemente el arriendo no estuvo difundido en forma pareja por toda la jurisdicción. Pero estaría asociado a la ocupación más intensiva de la campaña que había multiplicado su población, condicionado por la disponibilidad de tierras.

Sólo se han conservado cinco contratos protocolizados sobre arrendamientos de inmuebles rurales de particulares. Ellos se aplicaron tanto sobre suertes de tierras como sobre estancias completas.

Los términos de la duración del contrato eran variables pero en su mayoría rondaron los 4 ó 5 años. Las coyunturas económicas habrían favorecido en algunos casos la generalización del arrendamiento, fundamentalmente cuando se trataba de hacendados absentistas que arrendaban parte de sus estancias y cuando el arriendo incluía cargas vinculadas a suplir la mano de obra para las tareas agrícolas de los establecimientos. La ubicación de las tierras indica que los cinco casos de arrendamientos correspon-

48 Ibídem, Serie A, Caja 52, expte. 28, año 1808.

49 Mata de López, Sara: Persistencias y cambios: Salta y el noroeste argentino, 1770-1840, Rosario, Argentina, 1999.

50 AHT, SJC, Serie A, Caja 77, expte. 1, año 1840.

51 AHT, SA, vol. 40, fs. 179-180, año 1832. 
dían al curato de Burruyacu y el Rectoral. Recordemos que en el primero el sistema parece haber estado bastante difundido.

\section{CuAdRo 4}

\section{ARRENDATARIOS EN TIERRAS DE PARTICULARES}

\begin{tabular}{lllllll} 
Año & Propietarios & Arrendatarios & Tipo de inmueble & Ubicación & Canon* & Duración \\
\hline 1777 & M. ${ }^{\text {a }}$ Araoz & Manuel Rodríguez & suerte tierras & El Brete & $22 \mathrm{ps}$ & 9 años \\
1790 & M. $^{\text {a }}$ Artazar & Joaquín Monzón & suerte tierras & Potr. Los Usedos & $15 \mathrm{ps}$ & 5 años \\
1792 & Domingo Cabot & Antunez de Sousa & potrero & Los Sauces (Req.) & $25 \mathrm{ps}$ & 5 años \\
1794 & M. Balderrana & José don Ayala & estancia & San Pablo & $66 \mathrm{ps}$ & 4 años \\
1806 & M. $^{\text {a I. Toledo }}$ & Pedro J. Ramírez & tierras & Cerro Negro & $25 \mathrm{ps}$ & s/t
\end{tabular}

* el canon estipulado corresponde a cada año de arriendo.

Fuentes: Elaboración propia sobre datos del AHT, SA y SP

Más difícil es explicar la variación de los precios estipulados para el canon pues no podemos establecer la rentabilidad potencial de las tierras ni su extensión. Tampoco conocemos en forma clara las fluctuaciones coyunturales en esta materia. De cualquier modo creemos que es fundamental considerar el peso de la costumbre en el modo de estimar estos montos. No podemos asegurar que esta renta fija, pactada en pesos, excluyera otro tipo de obligaciones de montos variables de acuerdo con la producción obteni$\mathrm{da}$, o relaciones de servicio personal.

La vinculación entre la producción y la fuerza de trabajo en el caso de los arrendamientos es más difícil de precisar. También lo es el nivel de estabilidad relacionada con el acceso a la tierra. Estimamos que la producción de los arrendatarios estaba basada fundamentalmente en la fuerza de trabajo doméstica, aunque no podemos negar la existencia de arriendos de establecimientos completos que, como unidades productivas complejas, habrían generado la necesidad de acudir a mano de obra extrafamiliar.

Las ventajas del sistema de arriendos parecen haber sido múltiples para los propietarios que no residían en sus estancias o que lo hacían a tiempo parcial. Por este medio evitaban mayores inversiones de capital en sus establecimientos y eliminaban totalmente los riesgos que conllevaba la producción directa. Por otro lado este sistema se fundaba en la necesidad de tierras para quienes no tenían acceso a ellas o les resultaban insuficientes, a la vez que era una adecuada estrategia implementada por muchos pro- 
pietarios para la obtención de mano de obra estable o, al menos, de una renta segura, aunque no fuera de un nivel muy significativo. A veces los dueños cobraban un canon simbólico, signo de posesión más que una renta, pero que servía a los efectos de asegurarse el dominio jurídico de la tierra.

Las evidencias sobre pleitos desencadenados por los contratos sobre arrendamientos, dispersas de por sí, nos brindan otros indicios sobre este sistema, que demuestran el carácter conflictivo que muchas veces generaba la relación entre arrendatarios-propietarios o entre arrendatarios-vecinos propietarios.

Las relaciones entre los distintos actores sociales de la campaña estaban gobernadas por las "normas" y las "costumbres", muchas veces en clara contravención con la legislación que pretendía encauzar dichas prácticas o simplemente eliminarlas. Hacia fines del período colonial, y más aún durante el período independiente, la política del Estado apuntaba a controlar y reducir el sector conformado por los arrendatarios y agregados imponiéndoles serias restricciones a los propietarios. Respecto a los primeros se exigía que

"con el pretexto de arrendatarios no teniendo quando menos cien Bacas y cinquenta ovejas, de que para exhonerarse de dicha pena impuesta asi los Dueños de la tierra como los dichos Arrendatarios harán constar el contrato a las Justicias con expression del numero de dichas Bacas y Ovejas para su averiguacion correspondiente...". ${ }^{52}$

Algunos hombres de la Ilustración se hicieron eco de la revalorización de la producción agrícola y la necesidad de fomentar la pequeña y mediana propiedad. Criticaron el sistema de tenencias precarias y el trabajo rural por ser ineficaz y poco rentable para el Estado, acusando a los arrendatarios de ser "en la realidad langostas de las Haciendas, assi en que viven, como de los vexinos porque no haciendo mas costo su trabajo para la manutencion del año que un corto sembrado de legumbres, suplen sus urgencias con los haveres de los Hacendados". ${ }^{53}$

Esa imagen desprestigiada de quienes producían bajo arriendo o algún otro tipo de dependencia contrastaba con la realidad campesina — según se puede inferir de la misma legislación punitoria-, en la que existían arraifamilia...".

52 Ibídem, vol. 11, fs. 185-187v. También transcripción en López de Albornoz, "Población,

53 Los principales impulsores de esta política en Buenos Aires fueron Manuel Belgrano, Azara, Pedro Agustín García, Vieytes, mientras que sólo un par de tucumanos, Salvador Alberdi y Miguel Molina, pueden encuadrarse en esta línea. 
gadas relaciones de "reciprocidad" entre arrendatarios y propietarios. Así, por ejemplo, en la presentación que hizo doña María Rosa Robles viuda de don José Mateo Palavecino en 1772 contra doña María Palavecino por las tierras de Leales, se denunciaba que hacía años que la segunda ocupaba las tierras con el consentimiento de don Mateo, quien a la vez tenía "puestos en sus pertenencias a varios sujetos que le han pagado y pagan arrendamiento a D. ${ }^{a}$ María Rosa". ${ }^{54}$ En el pleito de don Antonio Brito contra Felipe Luna las declaraciones de los testigos coincidían en que

"D. Felipe Luna salió hace dos años hacia Chile dejando esposa e hija, que luego su suegra se llevó su familia a Catamarca y dejó un arrendero en su estancia situada en Leales, un tal Isidro Chorqueda, que ahora vive en Salta". ${ }^{55}$

Los casos mencionados nos remiten a dos tipos diferentes de arriendos (aunque suponemos que la variedad debió ser bastante amplia, como ocurría en otras zonas). ${ }^{56}$ El primero correspondía al arrendamiento de parcelas de tierras que procedían del fraccionamiento de una propiedad mayor. $\mathrm{Y}$ en ese caso arrenderos y propietarios podían contar con su propia producción. El segundo nos remite a la modalidad de arrendamiento de un establecimiento completo.

Hacia fines del siglo XVIII otro sistema de tenencia de la tierra en condición de préstamos (o arriendos de gracia, como se los ha denominado en otras regiones) aparecía difundido por la jurisdicción. Aún no está claro si esta práctica era sinónimo de la condición de agregado, que como se puede observar a través de los padrones tardocoloniales, estaba bastante difundida en el Virreinato. Pero a la larga este tipo de ocupación generaba serios conflictos entre los propietarios y los arrendatarios. Un caso ilustrativo fue el pleito iniciado por don José Antonio García contra Francisco Alzogaray donde declaraba que

"por inventarios ha heredado con su hermana D. ${ }^{a}$ Isabel García la estancia de Chañar Pugio, en la otra banda, en la que desde la muerte de su madre ha estado viviendo con porción de hacienda de campo Francisco Alzogaray, disfrutándola con ventajosos dividendos en sus haciendas como también de las crecidas sementeras de frutos y granos ya hace más de once años, sin pagar por esto ninguna pensión ni haberle hecho arrendamiento salvo por gracia de préstamo mi madre. Y aunque intentó que se vaya dándole plazo para buscar sitio no lo hizo".

54 AHT, SJC, Serie A, Caja 96, expte. 18. Sobre la estancia de Leales, 1772.

55 Ibídem, Caja 75, expte. 31. Autos sobre un potrero, 1838-1839.

56 Fradkin, R.: "La historia agraria...". 
García había intentado cobrarle, por cada año que Alzogaray venía ocupando las tierras, un arriendo de diez reses a su elección, precio que no fue aceptado por el demandado. El alcalde de primer voto estableció un plazo de dos meses para que Alzogaray dejara las tierras o debía pagar una multa de cien pesos. Hallándose enfermo Don Francisco, su mujer, Doña María Josefa Robles solicitó una ampliación del plazo, que le fue prorrogado por un año más. Interesante resulta el alegato de la parte demandada expresado en un fragmento del juicio, ya que nos informa sobre las características de los arrendamientos de gracia y los móviles para su posterior expulsión:

“...hace el término de diez a once años nos adjudicó D. Manuel García y D. ${ }^{a}$ Gabriela de Araoz su esposa, la enunciada estancia desierta, despoblada y sin ninguna utilidad para que la poblemos sin el más mínimo interés (...) en la que hemos trabajado en edificios, formando corrales, cultivando tierras y cercado el ojo de agua (...) de suerte que hoy tiene precio la citada estancia...". ${ }^{57}$

La precariedad y las restricciones impuestas a los arrendatarios saltan a la vista: solían ocupar tierras marginales y sin ningún tipo de laboreo previo; las trabajaban, a veces les introducían mejoras, pero al no tener derechos de propiedad podían ser expulsados en cualquier momento, según el antojo de los propietarios.

Otra forma de acceso a la tierra en condición de dependiente de un estanciero era la de los peones radicados con sus familias en las estancias, muchos de los cuales eran conocidos también como agregados. La documentación distingue claramente entre los peones jornaleros que se conchababan por un salario y los agregados peones radicados en las estancias. Esta última denominación denotaba siempre la condición de dependencia pero, a la vez, señalaba que tenían acceso a una parcela de tierra y que prestaban servicios en las estancias de los particulares.

En el padrón de población correspondiente al año 1799 se registraron familias de agregados y peones en varias unidades censales del curato de Trancas. El caso más significativo fue el de los agregados que vivían en la estancia del "Asequión", perteneciente a don Felipe Antonio López, alcalde del partido. Se trataba de seis familias, la mayoría compuesta por el jefe del grupo, la mujer y varios hijos. Dos de las unidades familiares contaban con pequeñas haciendas consistentes en una yunta de bueyes, varios caba-

57 AHT, SJC, Serie A, Caja 28, expte. 17. Sobre la estancia de Chañar Pugio, 1775. 
llos, unas vacas lecheras y algunas yeguas. Aquí la condición de agregado y peón pudo haber generado cierto tipo de "salario", pero no podemos asegurarlo, como tampoco podemos asegurar, por el momento, que la condición de conchabado no estuviera asociada también a la de agregado.

Hemos trabajado con los inventarios de dependientes que se registraron en otras estancias de Trancas y podemos ofrecer nuevos aportes sobre el tema. Por ejemplo, los indios foráneos, es decir aquellos que no eran originarios de los pueblos nativos de la región, como lo fueron los de Colalao, Tolombón y Chuscha, aparecían frecuentemente como dependientes tanto en los mismos pueblos como en las estancias. En el expediente judicial de los bienes de Andrés Donaire, indio foráneo casado con Isabel Colquema, india originaria de Chuscha, se indica que "viven" en el Potrero de Alurralde y habían logrado una pequeña fortuna hasta 1789, cuando se efectuaron los inventarios por la muerte de Isabel. No se especificó exactamente en qué condiciones vivían, pero sus bienes ascendían a 558,6 pesos, algo más del $10 \%$ del promedio de bienes de los estancieros de la región. La composición de ese capital indica que el $90 \%$ estaba constituido por haciendas ganaderas.

Pero no es el único ejemplo. Otra familia que vivía "en lo de Alurralde" eran los Gutiérrez. La muerte del jefe de familia, Baltasar, motivó la confección del inventario de bienes. En este caso, el capital ascendía a 428,4 pesos pero su composición era más variada: el $86 \%$ correspondía al ganado, casi el 3\% era el valor del rastrojo de trigo sembrado y el 2,5\% estaba constituido por herramientas para la siembra y la carpintería.

Otro caso ilustrativo era el de Cayetano Iriarte y su esposa Juana, "indios que residían en calidad de agregados en tierras de la frontera pertenecientes al Mro. D. Juan Ignacio Ruiz de la Vega" (en el paraje de El Brete). Sus bienes sumaban 497,6 pesos en el momento de los inventarios y el $98 \%$ consistía en ganado.

¿Qué nos sugieren estos ejemplos? Fundamentalmente que en las estancias del valle de Trancas la práctica de incorporar agregados u ocupantes de tierras estaba bastante difundida. No es fácil, sin embargo, determinar cuál pudo ser el grado de diferencia entre este sistema y los arrendamientos de gracia, aunque suponemos que ello estaba en relación con una mayor o menor dependencia del estanciero, a pesar de que tampoco está claro el tipo de prestaciones que conllevaba una u otra condición. Suponemos que, a cambio de permanecer en tierras ajenas, los agregados debían ayudar en todas las faenas del campo, a la vez que hacían sus pro- 
pias sementeras o criaban su propio ganado. Aquí también la línea divisoria con los arrendatarios que saldaban el canon del arriendo con prestaciones personales se vuelve muy difusa. Por otro lado, el monto de los bienes de los agregados en las estancias de Trancas indica que su condición no puede ser asociada con la del dependiente desposeído, y más bien sería una prueba por la cual algunos grupos campesinos habrían estado en condiciones de lograr una movilidad social ascendente mediante la posterior adquisición de tierras en propiedad. Un comentario más merece este análisis. Creemos que la difusión de la modalidad de este tipo de agregados-peones en el curato de Trancas y de los arrendatarios sujetos a canon que se detecta en Burruyacu pudo estar directamente vinculada con prácticas culturales diferenciadas. En el primer caso es posible que la persistencia de los pueblos indios más importantes de ella, sumado a las características de la producción agroganadera de la región, favoreciera la inmigración de familias altoperuanas que hubieran trasladado estas prácticas como parte de su bagaje cultural. Burruyacu, en cambio, se asemejaba más a los clásicos modelos de expansión de la frontera agrícola, caracterizados por la presencia de grandes estancias cuyas tierras marginales eran entregadas en arriendo para su explotación y rentabilidad.

\section{Conclusiones}

A modo de síntesis podemos decir que si bien la propiedad de la tierra no determinó la producción pues no todos los productores tuvieron acceso a un título de propiedad, en el mundo colonial ser vecino propietario permitía una ubicación privilegiada en la organización social, condicionada por sus características estamental y patrimonial.

Desde los comienzos de la colonización del territorio las mercedes rurales beneficiaron a los beneméritos que luego conformarían la base de la élite local, aunque muchos inmuebles se mantuvieron despoblados, generando disputas por los títulos y ocupaciones de hecho que, a la larga, provocaron el acceso de otros sectores rurales a la propiedad de las tierras.

Las familias propietarias implementaron diferentes mecanismos y estrategias que impidieron, en muchos casos, la rápida dispersión de los patrimonios por efecto de las herencias y las ventas. Prácticas muy elaboradas que incluían estrategias matrimoniales con una marcada endogamia de estrato y otras figuras previstas por el derecho castellano para la trans- 
misión de las propiedades inmuebles, como fueron las donaciones "intervivos" o de cláusula testamentaria y los patrimonios, así como los derechos de abolengo, la indivisibilidad de las tierras, las preferencias de algunos herederos en los repartos, se implementaron a los efectos de conservar la propiedad de la tierra.

Pero el fenómeno de fraccionamiento fue inevitable, no sólo por los efectos ya mencionados de la herencia, sino también por las coyunturas económicas, los cambios en los mercados, las frecuentes crisis de la producción agrícola y ganadera sujeta a los factores climáticos y a las plagas, e incluso las historias personales de los actores involucrados. A ello se sumó el crecimiento demográfico, la modificación de las estructuras indígenas y el surgimiento de un sector de trabajadores libres que pudo acceder a la compra de una parcela de tierra. Es por ello que, a fines del período colonial, el universo de los propietarios de inmuebles rurales era muy complejo y se encontraba sujeto a continuos cambios.

Como proceso concomitante, junto a la difusión de los pequeños propietarios se multiplicaron los arrendamientos de tierras y la presencia de agregados en las estancias, generando relaciones más complejas en la campaña.

Al finalizar el siglo XVIII el número de propietarios había crecido en detrimento del tamaño de las propiedades. Junto a la ocupación en condominios, arrendamientos e incluso asentamientos de hecho, los estratos inferiores a los estancieros accedieron a la tierra. La multiplicación de las familias campesinas, fruto del crecimiento vegetativo y de la migración, dio por resultado una ocupación más efectiva del espacio, a la vez que desencadenaba nuevas relaciones entre vecinos, estantes y habitantes, a veces armónicas, pero las más de ellas, muy conflictivas. Muchos de estos conflictos persisten actualmente. 